Supporting information

\title{
Synthesis of Acyl Terphenyls and Higher Polyaromatics via Base-Promoted C-H Functionalization of Acetylarenes with Arylacetylenes
}

Elena Yu. Schmidt, Elena V. Ivanova, Inna V. Tatarinova, Igor’ A. Ushakov, Nadezhda V. Semenova, Alexander V. Vashchenko, and Boris A. Trofimov*

A. E. Favorsky Irkutsk Institute of Chemistry, Siberian Branch, Russian Academy of Sciences, 1 Favorsky Str., 664033 Irkutsk, Russia 


\section{Table of Contents}

$\begin{array}{ll}\text { General Information } & \text { S3 }\end{array}$

$\begin{array}{ll}\text { General procedure for the synthesis of terphenyls } 4 & \text { S3 }\end{array}$

$\begin{array}{ll}\text { Characterization data of compound } \mathbf{4 a - 4 j}, \mathbf{5} & \text { S3 }\end{array}$

$\begin{array}{ll}\text { NMR Spectra } & \text { S10 }\end{array}$

$\begin{array}{lr}\text { X-Ray Diffraction Analysis } & \text { S30 }\end{array}$ 
General Information. ${ }^{1} \mathrm{H}$ and ${ }^{13} \mathrm{C}$ NMR spectra were recorded at 400.1 and $100.6 \mathrm{MHz}$ respectively equipped with an inverse gradient $5 \mathrm{~mm}$ probe in $\mathrm{CDCl}_{3}$ with hexamethyldisiloxane (HMDS) as an internal standard. The ${ }^{1} \mathrm{H}$ and ${ }^{13} \mathrm{C}$ chemical shifts were referenced to HMDS. Coupling constants are given in Hertz. IR spectra were taken with FTIR. The mass spectra (electron impact, $70 \mathrm{eV}$ ) were recorded on a Shimadzu GCMSQP5050A instrument. All chemicals and solvents are commercially available and were used without further purification. The elaborated procedure does not require degassing of DMSO and use of inert atmosphere and the benefit of DMSO as a solvent is that it is stable up to 150 ${ }^{\circ} \mathrm{C}$ for a long time $(24 \mathrm{~h}$, weight lost $0.1-1.0 \%) .{ }^{[1]}$

General procedure for the synthesis of terphenyls 4. A mixture of acetylarene 1 (5 mmol), arylacetylene $2(5 \mathrm{mmol})$ and $\mathrm{KOBu}^{\mathrm{t}}(0.561 \mathrm{~g}, 5 \mathrm{mmol})$ in DMSO $(15 \mathrm{~mL})$ was heated (100 $\left.{ }^{\circ} \mathrm{C}\right)$ and stirred at $100{ }^{\circ} \mathrm{C}$ for $30 \mathrm{~min}$. Then $\mathrm{MeCOOH}(0.200 \mathrm{~g}, 3.3 \mathrm{mmol})$ was added and the reaction mixture was stirred at $100{ }^{\circ} \mathrm{C}$ for $4 \mathrm{~h}$. The reaction mixture, after cooling (rt), was diluted with $\mathrm{H}_{2} \mathrm{O}(15 \mathrm{~mL})$, neutralized with $\mathrm{NH}_{4} \mathrm{Cl}$ and was extracted with $\mathrm{Et}_{2} \mathrm{O}(10 \mathrm{~mL} \times 4)$. The organic extract was washed with $\mathrm{H}_{2} \mathrm{O}(5 \mathrm{~mL} \times 3)$ and dried $\left(\mathrm{MgSO}_{4}\right) \cdot \mathrm{Et}_{2} \mathrm{O}$ was evaporated in vacuum and the residue was purified by column chromatography $\left(\mathrm{Al}_{2} \mathrm{O}_{3}\right.$, eluent hexane/ $\mathrm{Et}_{2} \mathrm{O}$ with gradient from 1:0 to $10: 1$ ).

Phenyl[1, 1'; 4', 1'’]terphenyl-2'-yl-methanone (4a).<smiles>O=C(c1ccccc1)c1cc(-c2ccccc2)ccc1-c1ccccc1</smiles>

Following GP, 4a was prepared from acetophenone 1a (0.605 g, $5.0 \mathrm{mmol})$, phenylacetylene $2 \mathrm{a}(0.510 \mathrm{~g}, 5.0 \mathrm{mmol}), \mathrm{KOBu}^{\mathrm{t}}(0.561 \mathrm{~g}, 5.0 \mathrm{mmol})$ and $\mathrm{MeCOOH}(0.200 \mathrm{~g}, 3.3 \mathrm{mmol})$. The crude product was purified by column chromatography (hexane/ $\mathrm{Et}_{2} \mathrm{O}$ with gradient from 1:0 to $10: 1)$. 4a was isolated as a white solid (0.602 g, 72\% yield); m.p. $124-126{ }^{\circ} \mathrm{C}$ (lit. ${ }^{[2]} \mathrm{m} . \mathrm{p}$. $135{ }^{\circ} \mathrm{C}$ ); elemental analysis calcd (\%) for $\mathrm{C}_{25} \mathrm{H}_{18} \mathrm{O}$ (334.41): C 89.79\%; H 5.43\%; found: C $89.60 \%$; H $5.50 \%$.

[1] Dimethyl sulfoxide (DMSO). Technical Bulletin. Crown Zellerbach Chemical Products Division, Vancouver (Orchards), WA 98662, 1985.

[2] N. Asao, H. Aikawa, J. Org. Chem. 2006, 71, 5249. 
IR (film): $v_{\max } 3436,1665,1594,1475,1448,1339,1240,761,748,723,699 \mathrm{~cm}^{-1}$; ${ }^{1} \mathbf{H}$ NMR (400.1 MHz, $\left.\mathbf{C D C l}_{3}\right): \delta 7.78(\mathrm{dd}, J=8.0,1.6 \mathrm{~Hz}, 1 \mathrm{H}), 7.71(\mathrm{~d}, J=1.6 \mathrm{~Hz}, 1 \mathrm{H}), 7.70-7.64$ (m, 2H), $7.63-7.60(\mathrm{~m}, 2 \mathrm{H}), 7.54(\mathrm{~d}, J=8.0 \mathrm{~Hz}, 1 \mathrm{H}), 7.46-7.40(\mathrm{~m}, 2 \mathrm{H}), 7.39-7.33(\mathrm{~m}$, 2H), $7.30-7.25$ (m, 3H), $7.23-7.10$ (m, 4H) ppm; ${ }^{13}$ C NMR (100.6 MHz, $\left.\mathbf{C D C l}_{3}\right): \delta 198.9$, $140.3,140.0$, 139.7, 137.6, 133.1, 130.8, 130.2, 129.2, 129.1, 129.0, 128.5, 128.4, 128.0, 127.6, 127.5, $127.3 \mathrm{ppm}$; MS (EI) m/z (\%) 334 (M+, 100).

Phenyl[1, 1'; 4', 1'; 4", 1"']quarterphenyl-2'-yl-methanone (4b).

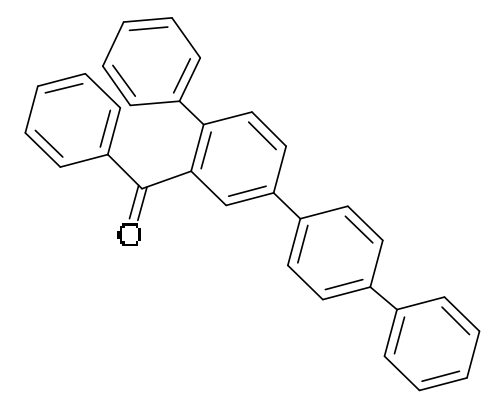

Following GP, 4b was prepared from acetophenone 1a (0.605 g, $5.0 \mathrm{mmol})$, 4-ethynyl-1,1'biphenyl 2b (0.891 g, $5.0 \mathrm{mmol}), \mathrm{KOBu}^{\mathrm{t}}(0.561 \mathrm{~g}, 5.0 \mathrm{mmol})$ and $\mathrm{MeCOOH}(0.200 \mathrm{~g}, 3.3$ mmol). The crude product was purified by column chromatography (hexane/ $\mathrm{Et}_{2} \mathrm{O}$ with gradient from 1:0 to 10:1). 4b was isolated as a white solid $(0.821 \mathrm{~g}, 80 \%$ yield); m.p. 179$181{ }^{\circ} \mathrm{C}$; elemental analysis calcd (\%) for $\mathrm{C}_{31} \mathrm{H}_{22} \mathrm{O}$ (410.51): $\mathrm{C} 90.70 \%$; $\mathrm{H} \mathrm{5.40 \%}$; found: $\mathrm{C}$ $90.57 \%$; H $5.49 \%$.

IR (film): $v_{\max } 3059,3028,2925,2854,1662,1597,1580,1546,1476,1448,1410,1389$, 1318, 1296, 1261, 1241, 1178, 1157, 1118, 1075, 1020, 1007, 947, 830, 765, 733, 698, 648, 616, 534, $503 \mathrm{~cm}^{-1} ;{ }^{1} \mathbf{H}$ NMR (400.1 MHz, $\left.\mathbf{C D C l}_{3}\right): \delta 7.90-7.82(\mathrm{~m}, 3 \mathrm{H}), 7.77(\mathrm{dd}, J=8.0$, $1.8 \mathrm{~Hz}, 1 \mathrm{H}), 7.55-7.43(\mathrm{~m}, 6 \mathrm{H}), 7.42-7.37(\mathrm{~m}, 2 \mathrm{H}), 7.35-7.29(\mathrm{~m}, 2 \mathrm{H}), 7.25-7.12(\mathrm{~m}$, 8H) ppm; ${ }^{13} \mathbf{C}$ NMR (100.6 MHz, $\left.\mathbf{C D C l}_{3}\right): \delta$ 198.7, 140.6, 139.6, 133.0, 132.3, 130.7, 130.3, $130.0,129.8,129.1,128.9,128.8,128.7,128.4,128.2,127.7,127.5,127.3,127.1,127.0$, $126.8 \mathrm{ppm} ; \mathrm{MS}(\mathrm{EI}) \mathrm{m} / \mathrm{z}(\%) 410(\mathrm{M}+, 100)$.

(4-Methyl-[1, 1'; 4', 1',]terphenyl-2'-yl)-p-tolyl-methanone (4c).<smiles>Cc1ccc(C(=O)c2cc(-c3ccccc3)ccc2-c2ccc(C)cc2)cc1</smiles> 
Following GP, 4c was prepared from 4-methylacetophenone $1 \mathbf{b}(0.671 \mathrm{~g}, 5.0 \mathrm{mmol})$, phenylacetylene $2 \mathrm{a}(0.510 \mathrm{~g}, 5.0 \mathrm{mmol}), \mathrm{KOBu}^{\mathrm{t}}(0.561 \mathrm{~g}, 5.0 \mathrm{mmol})$ and $\mathrm{MeCOOH}(0.200 \mathrm{~g}$, $3.3 \mathrm{mmol}$ ). The crude product was purified by column chromatography (hexane/Et ${ }_{2} \mathrm{O}$ with gradient from 1:0 to 10:1). 4c was isolated as a white solid (0.607 g, 67\% yield); m.p. 136$138{ }^{\circ} \mathrm{C}$; elemental analysis calcd (\%) for $\mathrm{C}_{27} \mathrm{H}_{22} \mathrm{O}$ (362.46): $\mathrm{C} 89.47 \%$; $\mathrm{H} 6.12 \%$; found: $\mathrm{C}$ $89.25 \%$; H $6.20 \%$.

IR (film): $v_{\max } 3057,3028,2920,2858,1662,1604,1570,1522,1477,1450,1408,1389$, 1314, 1295, 1261, 1240, 1210, 1180, 1154, 1115, 1076, 1022, 1006, 949, 897, 841, 817, 781, 763, 698, 640, 609, 575, 538, 501, $479 \mathrm{~cm}^{-1} ;{ }^{1} \mathbf{H}$ NMR (400.1 MHz, $\left.\mathbf{C D C l}_{3}\right): \delta 7.74(\mathrm{dd}, J=$ 8.0, $1.8 \mathrm{~Hz}, 1 \mathrm{H}), 7.70-7.58(\mathrm{~m}, 5 \mathrm{H}), 7.52$ (d, $J=8.0 \mathrm{~Hz}, 1 \mathrm{H}), 7.47-7.37$ (m, 2H), $7.36-$ $7.28(\mathrm{~m}, 1 \mathrm{H}), 7.25-7.17(\mathrm{~m}, 2 \mathrm{H}), 7.15-7.06(\mathrm{~m}, 2 \mathrm{H}), 7.05-6.99(\mathrm{~m}, 2 \mathrm{H}), 2.29(\mathrm{~s}, 3 \mathrm{H})$, 2.23 (s, 3H) ppm; ${ }^{13} \mathbf{C}$ NMR (100.6 MHz, $\left.\mathbf{C C l}_{4}\right): \delta 195.7,142.1,139.9,139.7,139.4,139.2$, $136.9,136.0,134.9,129.9,129.7,128.6,128.5,128.4,128.3,127.8,127.2,126.8,21.4,20.9$ ppm; MS (EI) m/z (\%) $362(\mathrm{M}+, 100)$.

(4,4'’-Dimethyl-[1, 1'; 4', 1'’]terphenyl-2'-yl)-p-tolyl-methanone(4d).

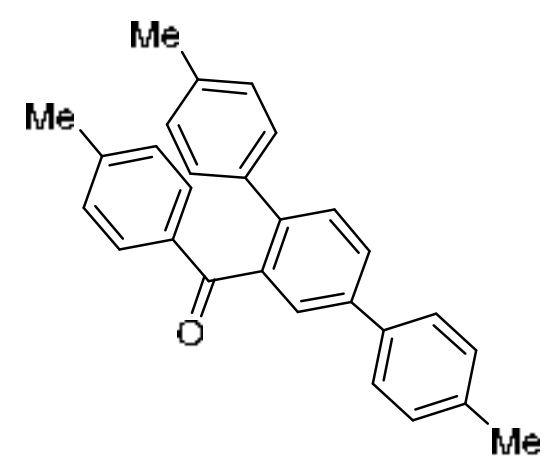

Following GP, 4d was prepared from 4-methylacetophenone $\mathbf{1 b}(0.671 \mathrm{~g}, 5.0 \mathrm{mmol})$, 4tolylacetylene $2 \mathrm{c}(0.581 \mathrm{~g}, 5.0 \mathrm{mmol}), \mathrm{KOBu}^{\mathrm{t}}(0.561 \mathrm{~g}, 5.0 \mathrm{mmol})$ and $\mathrm{MeCOOH}(0.200 \mathrm{~g}$, $3.3 \mathrm{mmol}$ ). The crude product was purified by column chromatography (hexane/Et ${ }_{2} \mathrm{O}$ with gradient from 1:0 to 10:1). 4d was isolated as a white solid (0.723 g, 77\% yield); m.p. 152$154{ }^{\circ} \mathrm{C}$; elemental analysis calcd (\%) for $\mathrm{C}_{28} \mathrm{H}_{24} \mathrm{O}$ (376.49): $\mathrm{C} 89.33 \%$; $\mathrm{H} 6.43 \%$; found: $\mathrm{C}$ $89.23 \%$; H $5.52 \%$.

IR (film): $v_{\max } 3019,2912,1656,1603,1481,1312,1302,1243,1017,1005,906,841,822$, 808, 773, 736, 683, 605, 540, 504, $479 \mathrm{~cm}^{-1}$; ${ }^{1} \mathbf{H}$ NMR (400.1 MHz, $\left.\mathbf{C D C l}_{3}\right): \delta 7.73(J=8.0$, $1.8 \mathrm{~Hz}, 1 \mathrm{H}$ ), $7.65-7.59(\mathrm{~m}, 3 \mathrm{H}), 7.55-7.47(\mathrm{~m}, 3 \mathrm{H}), 7.25-7.20(\mathrm{~m}, 2 \mathrm{H}), 7.20-7.15(\mathrm{~m}$, 2H), $7.11-7.05(\mathrm{~m}, 2 \mathrm{H}), 7.03-6.97(\mathrm{~m}, 2 \mathrm{H}), 2.38(\mathrm{~s}, 3 \mathrm{H}), 2.32(\mathrm{~s}, 3 \mathrm{H}), 2.25(\mathrm{~s}, 3 \mathrm{H}) \mathrm{ppm}$; ${ }^{13}$ C NMR (100.6 MHz, $\left.\mathbf{C D C l}_{3}\right): \delta$ 198.3, 143.8, 139.6, 139.5, 137.5, 137.1, 137.0, 134.9, 
130.6, 130.3, 129.6, 129.0, 128.9, 128.8, 126.9, 21.6, 21.1 ppm; MS (EI) m/z (\%) 376 (M+, $100)$.

(4 -Fluoro-phenyl)-(4-fluoro-[1, 1'; 4', 1'']terphenyl-2'-yl)-methanone (4e).<smiles>O=C(c1ccc(F)cc1)c1cc(-c2ccccc2)ccc1-c1ccc(F)cc1</smiles>

Following GP, 4e was prepared from 4-fluoroacetophenone 1c (0.691 g, $5.0 \mathrm{mmol})$, phenylacetylene $2 \mathrm{a}(0.510 \mathrm{~g}, 5.0 \mathrm{mmol}), \mathrm{KOBu}^{\mathrm{t}}(0.561 \mathrm{~g}, 5.0 \mathrm{mmol})$ and $\mathrm{MeCOOH}(0.200 \mathrm{~g}$, $3.3 \mathrm{mmol}$ ). The crude product was purified by column chromatography (hexane/Et $\mathrm{E}_{2} \mathrm{O}$ with gradient from 1:0 to 10:1). 4e was isolated as a white solid $(0.491 \mathrm{~g}, 53 \%$ yield $)$; m.p. 128$130{ }^{\circ} \mathrm{C}$; elemental analysis calcd (\%) for $\mathrm{C}_{25} \mathrm{H}_{16} \mathrm{~F}_{2} \mathrm{O}$ (370.39): $\mathrm{C} 81.07 \%$; $\mathrm{H} 4.35 \%$; F 10.26\%; found: C $79.90 \%$; H 4.41\%; F 10.35\%.

IR (film): $v_{\max }$ 3064, 3031, 2918, 28503, 1664, 1596, 1519, 1504, 1476, 1449, 1411, 1388, 1311, 1296, 1259, 1238, 1180, 1151, 1121, 1096, 1076, 1027, 1014, 952, 945, 907, 851, 831, 817, 790, 764, 745, 7334, 698, 665, 635, 606, 574, 541, $502 \mathrm{~cm}^{-1} ;{ }^{1}$ H NMR (400.1 MHz, $\left.\mathbf{C D C l}_{3}\right): \delta 7.78(\mathrm{dd}, J=8.1,1.8 \mathrm{~Hz}, 1 \mathrm{H}), 7.72-7.65(\mathrm{~m}, 3 \mathrm{H}), 7.64-7.60(\mathrm{~m}, 2 \mathrm{H}), 7.50(\mathrm{~d}, J$ $=8.1 \mathrm{~Hz}, 1 \mathrm{H}), 7.47-7.41(\mathrm{~m}, 2 \mathrm{H}), 7.39-7.33(\mathrm{~m}, 1 \mathrm{H}), 7.27-7.20(\mathrm{~m}, 2 \mathrm{H}), 6.99-6.86(\mathrm{~m}$, 4H) ppm; ${ }^{13}$ C NMR (100.6 MHz, $\left.\mathbf{C D C l}_{3}\right): \delta 197.1,165.7$ (d, $\left.J=255.6 \mathrm{~Hz}\right), 162.4$ (d, $J=$ $248.3 \mathrm{~Hz}), 140.5,139.7,139.3,138.8,137.7,135.9$ (d, $J=3.3 \mathrm{~Hz}), 133.8$ (d, $J=3.0 \mathrm{~Hz})$, $132.6(\mathrm{~d}, J=9.0 \mathrm{~Hz}), 130.7$ (d, $J=8.8 \mathrm{~Hz}), 129.1,128.0,127.3,127.2,115.5$ (d, $J=21.8 \mathrm{~Hz})$, 115.4 (d, $J=22.0 \mathrm{~Hz}$ ) ppm; MS (EI) m/z (\%) 370 (M+, 100).

(4-Chloro-3'"-fluoro-[1, 1'; 4', 1'] terphenyl-2'-yl)-(4-chloro-phenyl)-methanone (4f).<smiles>O=C(c1ccc(Cl)cc1)c1cc(-c2cccc(F)c2)ccc1-c1ccc(Cl)cc1</smiles> 
Following GP, 4f was prepared from 4-chloroacetophenone 1d (0.773 g, $5.0 \mathrm{mmol})$, 3fluorophenylacetylene $2 \mathrm{~d}(0.600 \mathrm{~g}, 5.0 \mathrm{mmol}), \mathrm{KOBu}^{\mathrm{t}}(0.561 \mathrm{~g}, 5.0 \mathrm{mmol})$ and $\mathrm{MeCOOH}$ (0.200 g, $3.3 \mathrm{mmol})$. The crude product was purified by column chromatography (hexane/ $\mathrm{Et}_{2} \mathrm{O}$ with gradient from 1:0 to $\left.10: 1\right)$. 4f was isolated as a white solid $(0.579 \mathrm{~g}, 55 \%$ yield); m.p. $138-140{ }^{\circ} \mathrm{C}$; elemental analysis calcd (\%) for $\mathrm{C}_{25} \mathrm{H}_{15} \mathrm{Cl}_{2} \mathrm{FO}$ (421.29): $\mathrm{C} 71.27 \%$; H 3.59\%; Cl 16.83\%; F 4.51\%; found: C 71.35\%; H 4.01\%; Cl 16.86\%; F 4.48\%.

IR (film): $v_{\max } 3068,3032,2961,2925,2853,1660,1599,1585,1517,1475,1420,1400$, 1385, 1314, 1292, 1233, 1180, 1159, 1142, 1013, 1004, 948, 940, 906, 845, 827, 820, 793, 773, 737, 681, 616, 592,538, 516, $475 \mathrm{~cm}^{-1}$; ${ }^{1} \mathbf{H}$ NMR (400.1 MHz, $\left.\mathbf{C D C l}_{3}\right): \delta 7.75$ (dd, $J=$ 8.1, $1.7 \mathrm{~Hz}, 1 \mathrm{H}), 7.64(\mathrm{~d}, J=1.7 \mathrm{~Hz}, 1 \mathrm{H}), 7.63-7.55(\mathrm{~m}, 4 \mathrm{H}), 7.51(\mathrm{~d}, J=8.1 \mathrm{~Hz}, 1 \mathrm{H}), 7.30$ - $7.25(\mathrm{~m}, 2 \mathrm{H}), 7.22-7.18(\mathrm{~m}, 4 \mathrm{H}), 7.17-7.10$ (m, 2H) ppm; ${ }^{13} \mathbf{C}$ NMR (100.6 MHz, $\left.\mathbf{C D C l}_{3}\right): \delta 197.2,169.9(\mathrm{~d}, J=247.8 \mathrm{~Hz}), 139.8,139.6,139.0,138.6,138.0,135.7,135.5$, $133.9,131.3,130.7,130.2,129.1,128.9,127.2,116.0(\mathrm{~d}, J=21.5 \mathrm{~Hz}) \mathrm{ppm}$.

\section{Biphenyl-4-yl-[1, 1'; 4', 1"; 4", 1"']quarterphenyl-2"'-yl-methanone (4g).}

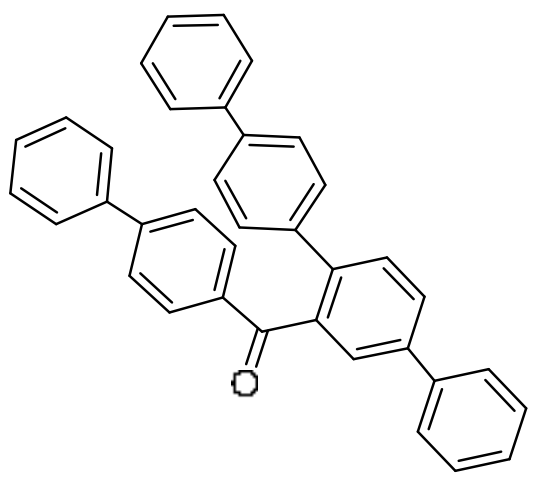

Following GP, 4g was prepared from 4-acetyl-1,1'-biphenyl 1e (0.981 g, 5.0 mmol), phenylacetylene $2 \mathrm{a}(0.510 \mathrm{~g}, 5.0 \mathrm{mmol}), \mathrm{KOBu}^{\mathrm{t}}(0.561 \mathrm{~g}, 5.0 \mathrm{mmol})$ and $\mathrm{MeCOOH}(0.200 \mathrm{~g}$, $3.3 \mathrm{mmol}$ ). The crude product was purified by column chromatography (hexane/Et $\mathrm{E}_{2} \mathrm{O}$ with gradient from 1:0 to 10:1). 4g was isolated as a white solid $(0.827 \mathrm{~g}, 68 \%$ yield); m.p. 186$188{ }^{\circ} \mathrm{C}$; elemental analysis calcd (\%) for $\mathrm{C}_{37} \mathrm{H}_{26} \mathrm{O}$ (486.60): $\mathrm{C} 91.33 \%$; $\mathrm{H} \mathrm{5.39 \%}$; found: $\mathrm{C}$ $91.76 \%$; H 5.35\%.

IR (film): $v_{\max } 3437,1663,1598,1477,1447,1404,1313,1271,1183,1154,1117,1076$, $1007,994,907,856,835,788,771,759,752,741,728,698,684,643,612,560,505 \mathrm{~cm}^{-1} ;{ }^{1} \mathbf{H}$ NMR (400.1 MHz, CDCl $)$ ): $\delta 7.85-7.77$ (m, 3H), $7.76(\mathrm{~d}, J=1.8 \mathrm{~Hz}, 1 \mathrm{H}), 7.69-7.63$ (m, 2H), $7.61(\mathrm{~d}, J=8.0 \mathrm{~Hz}, 1 \mathrm{H}), 7.55-7.49(\mathrm{~m}, 5 \mathrm{H}), 7.48-7.42(\mathrm{~m}, 5 \mathrm{H}), 7.41-7.32(\mathrm{~m}, 8 \mathrm{H})$, 7.31 - 7.25 (m, 1H) ppm; ${ }^{13}$ C NMR (100.6 MHz, $\left.\mathbf{C D C l}_{3}\right): \delta$ 198.2, 145.8, 140.7, 140.3, $140.2,139.7,139.6,138.2,136.2,130.7,129.5,129.1,129.0,128.8,128.3,127.9,127.4$, 127.2, 127.1, $127.0 \mathrm{ppm}$. 


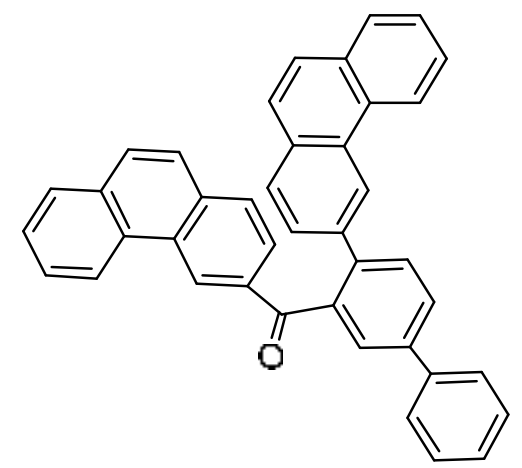

Following GP, 4h was prepared from 2-acetylphenanthrene 1f (1.101 g, $5.0 \mathrm{mmol})$, phenylacetylene $2 \mathrm{a}(0.510 \mathrm{~g}, 5.0 \mathrm{mmol}), \mathrm{KOBu}^{\mathrm{t}}(0.561 \mathrm{~g}, 5.0 \mathrm{mmol})$ and $\mathrm{MeCOOH}(0.200 \mathrm{~g}$, $3.3 \mathrm{mmol}$ ). The crude product was purified by column chromatography (hexane/Et ${ }_{2} \mathrm{O}$ with gradient from 1:0 to 10:1). 4h was isolated as a white solid $(0.815 \mathrm{~g}, 61 \%$ yield); m.p. 176$178{ }^{\circ} \mathrm{C}$; elemental analysis calcd (\%) for $\mathrm{C}_{41} \mathrm{H}_{26} \mathrm{O}$ (534.64): $\mathrm{C} 92.11 \%$; $\mathrm{H} 4.90 \%$; found: $\mathrm{C}$ 91.68\%; H 5.03\%.

IR (film): $v_{\max } 3055,3026,2960,2925,2853,1661,1621,1597,1571,1525,1482,1460$, 1448, 1423, 1384, 1352, 1314, 1261, 1235, 1213, 1193, 1180, 1142, 1121, 1093, 1076, 1024, 1000, 972, 900, 864, 844, 827, 810, 798, 746, 714, 698, 680, 667, $618 \mathrm{~cm}^{-1} ;{ }^{1}$ H NMR (400.1 MHz, $\left.\mathbf{C D C l}_{3}\right): \delta 8.55-8.48(\mathrm{~m}, 2 \mathrm{H}), 8.47-8.40(\mathrm{~m}, 2 \mathrm{H}), 8.22(\mathrm{~d}, J=1.6 \mathrm{~Hz}, 1 \mathrm{H}), 8.02(\mathrm{dd}$, $J=8.6,1.6 \mathrm{~Hz}, 1 \mathrm{H}), 7.92-7.83(\mathrm{~m}, 3 \mathrm{H}), 7.82-7.72(\mathrm{~m}, 3 \mathrm{H}), 7.71-7.67$ (m, 2H), $7.66-$ $7.60(\mathrm{~m}, 3 \mathrm{H}), 7.59-7.53(\mathrm{~m}, 4 \mathrm{H}), 7.52-7.42(\mathrm{~m}, 4 \mathrm{H}), 7.40-7.33(\mathrm{~m}, 1 \mathrm{H}) \mathrm{ppm} ;{ }^{13} \mathbf{C} \mathbf{N M R}$ (100.6 MHz, $\mathbf{C D C l}$ ): $\delta$ 198.4, 140.2, 139.8, 138.0, 135.1, 133.4, 133.0, 132.0, 131.9, 131.8, $131.1,131.0,130.0,129.9129 .6,129.4,129.0,128.9,128.7,128.5,128.4,127.8,127.7$, $127.4,127.3,127.2$, 127.1, 126.9, 126.8, 126.5, 126.4, 126.3, 123.3, 123.0, 122.9, 122.6 ppm.

(4'-Methyl-4-phenanthren-9-yl-biphenyl-3-yl)-phenanthren-2-yl-methanon (4i).

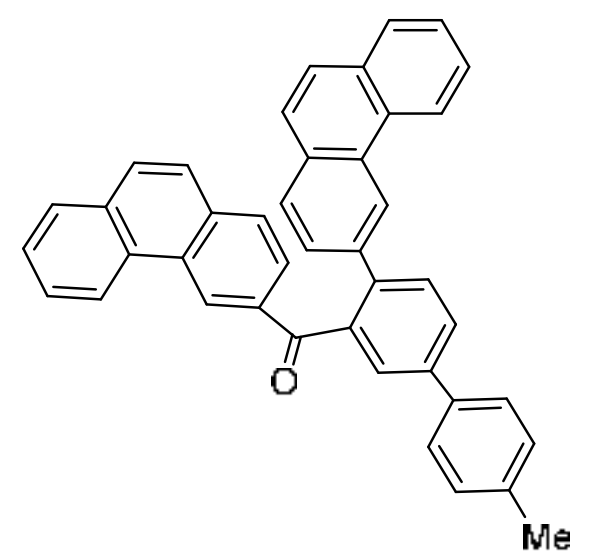

Following GP, 4i was prepared from 2-acetylphenanthrene 1f (1.101 g, 5.0 mmol), 4tolylacetylene $2 \mathrm{c}(0.581 \mathrm{~g}, 5.0 \mathrm{mmol}), \mathrm{KOBu}^{\mathrm{t}}(0.561 \mathrm{~g}, 5.0 \mathrm{mmol})$ and $\mathrm{MeCOOH}(0.200 \mathrm{~g}$, 
$3.3 \mathrm{mmol}$ ). The crude product was purified by column chromatography (hexane/Et $\mathrm{E}_{2} \mathrm{O}$ with gradient from 1:0 to 10:1). 4i was isolated as a white solid (0.946 g, 69\% yield); m.p. 226-228 ${ }^{\circ} \mathrm{C}$; elemental analysis calcd (\%) for $\mathrm{C}_{42} \mathrm{H}_{28} \mathrm{O}$ (548.67): $\mathrm{C} 91.94 \%$; $\mathrm{H} 5.14 \%$; found: $\mathrm{C}$ $91.78 \%$; H $5.28 \%$.

IR (film): $v_{\max } 3052,3025,2920,2853,1661,1622,1597,1571,1524,1488,1460,1423$, 1384, 1352, 1315, 1262, 1235, 1213, 1193, 1180, 1142, 1121, 1093, 1076, 1019, 1001, 973, 905, 865, 858, 812, 785, 762, 745, 714, 676, 648, 620, $512 \mathrm{~cm}^{-1} ;{ }^{1} \mathbf{H}$ NMR (400.1 MHz, $\left.\mathbf{C D C l}_{3}\right): \delta 8.41-8.57(\mathrm{~m}, 4 \mathrm{H}), 8.23(\mathrm{~d}, J=1.7 \mathrm{~Hz}, 1 \mathrm{H}), 8.04(\mathrm{dd}, J=8.8,1.7 \mathrm{~Hz}, 1 \mathrm{H}), 7.91$ $7.83(\mathrm{~m}, 3 \mathrm{H}), 7.82-7.71(\mathrm{~m}, 3 \mathrm{H}), 7.68-7.55(\mathrm{~m}, 9 \mathrm{H}), 7.53-7.45(\mathrm{~m}, 2 \mathrm{H}), 7.30-7.24(\mathrm{~m}$, 2H), 2.39 (s, 3H) ppm; ${ }^{13}$ C NMR (100.6 MHz, $\mathbf{C D C l}_{3}$ ): $\delta$ 198.6, 140.1, 139.8, 139.4, 138.1, $137.8,136.9,135.1,133.4,133.0,132.0,131.9,131.8,131.1,130.0129 .9,129.7,129.6$, $129.3,128.8,128.7,128.6,128.4,127.7,127.3,127.2,126.0,126.8,126.5,126.4,123.3$, $122.9,122.7,21.2 \mathrm{ppm}$.

\section{Thiophen-2-yl-(4-thiophen-2-yl-biphenyl-3-yl)-methanone (4j).}

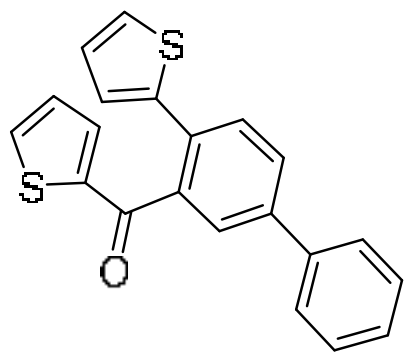

Following GP, 4j was prepared from 2-acetylthiophene $\mathbf{1 g}(0.631 \mathrm{~g}, 5.0 \mathrm{mmol})$, phenylacetylene $2 \mathrm{a}(0.510 \mathrm{~g}, 5.0 \mathrm{mmol}), \mathrm{KOBu}^{\mathrm{t}}(0.561 \mathrm{~g}, 5.0 \mathrm{mmol})$ and $\mathrm{MeCOOH}(0.200 \mathrm{~g}$, $3.3 \mathrm{mmol}$ ). The crude product was purified by column chromatography (hexane/Et ${ }_{2} \mathrm{O}$ with gradient from 1:0 to 10:1). $\mathbf{4 j}$ was isolated as a white solid (0.563 g, 65\% yield); m.p. 122-124 ${ }^{\circ} \mathrm{C}$; elemental analysis calcd (\%) for $\mathrm{C}_{21} \mathrm{H}_{14} \mathrm{OS}_{2}$ (346.47): $\mathrm{C} 72.80 \%$; $\mathrm{H} 4.07 \%$; $\mathrm{S} 18.51 \%$; found: C $73.0 \%$; H 3.95\%; S 18.60\%.

IR (film): $v_{\max } 3103,3087,3073,3030,2917,2850,1646,1600,1581,1552,1530,1514$, $1479,1448,1430,1411,1390,1354,1314,1285,1253,1231,1208,1180,1154,1112,1077$, 1047, 1024, 959, 908, 891, 857, 849, 829, 788, 763, 728, 698, 671, 665, 654, 612, 582, 565, 513, 487, $464 \mathrm{~cm}^{-1}$; ${ }^{1} \mathbf{H}$ NMR (400.1 MHz, $\left.\mathbf{C D C l}_{3}\right): \delta 7.73(\mathrm{dd}, J=8.1,1.6 \mathrm{~Hz}, 1 \mathrm{H}), 7.70(\mathrm{~d}$, $J=1.6 \mathrm{~Hz}, 1 \mathrm{H}), 7.64(\mathrm{~d}, J=8.1 \mathrm{~Hz}, 1 \mathrm{H}), 7.62-7.56(\mathrm{~m}, 3 \mathrm{H}), 7.48-7.39(\mathrm{~m}, 2 \mathrm{H}), 7.38-$ $7.32(\mathrm{~m}, 1 \mathrm{H}), 7.31-7.28(\mathrm{~m}, 1 \mathrm{H}), 7.20-7.17(\mathrm{~m}, 1 \mathrm{H}), 7.06-7.00(\mathrm{~m}, 1 \mathrm{H}), 6.97-6.92(\mathrm{~m}$, 1H), 6.89 - 6.85 (m, 1H) ppm; ${ }^{13}$ C NMR (100.6 MHz, $\left.\mathbf{C D C l}_{3}\right): \delta 190.5,144.6,141.2,140.4$, 
$139.6,139.3,135.4,134.9,131.6,130.8,129.0,128.8,128.1,127.8,127.4,127.1,126.8$, 126.4 ppm; MS (EI) m/z (\%) $346(\mathrm{M}+, 100)$.

\section{4-Methyl-1,1'-biphenyl (5).}

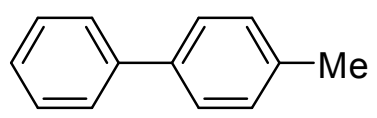

Following GP, 5 was obtained from acetophenone 1a (0.605 g, $5.0 \mathrm{mmol})$, 4-ethynyl-1,1'biphenyl 2b (0.891 g, $5.0 \mathrm{mmol}), \mathrm{KOBu}^{\mathrm{t}}(0.561 \mathrm{~g}, 5.0 \mathrm{mmol})$ and $\mathrm{MeCOOH}(0.200 \mathrm{~g}, 3.3$ $\mathrm{mmol}$ ). The crude product was purified by column chromatography (hexane). $\mathbf{5}$ was isolated as a white solid $(0.172 \mathrm{~g}, 41 \%$ yield $)$; m.p. $42-44{ }^{\circ} \mathrm{C}$ (lit. ${ }^{[3]}$ m.p. $\left.45-49{ }^{\circ} \mathrm{C}\right)$; elemental analysis calcd (\%) for $\mathrm{C}_{13} \mathrm{H}_{12}$ (168.23): C 92.81\%; H 7.19\%; found: C 93.01\%; H 7.04\%.

IR (film): $v_{\max } 3030,2922,2855,1488,1445,1403,1340,1128,1113,1076,1039,1008$, 910, 842, 823, 787, 755, 690, 617, 559, 546, $476 \mathrm{~cm}^{-1}$; ${ }^{1} \mathbf{H}$ NMR (400.1 MHz, $\left.\mathbf{C D C l}_{3}\right): \delta 7.45$ $(\mathrm{d}, 2 \mathrm{H}), 7.36(\mathrm{~d}, 2 \mathrm{H}), 7.29(\mathrm{t}, 2 \mathrm{H}), 7.19(\mathrm{t}, 1 \mathrm{H}), 7.11(\mathrm{~d}, 2 \mathrm{H}), 2.29(\mathrm{~s}, 3 \mathrm{H}) \mathrm{ppm} ;{ }^{13} \mathbf{C} \mathbf{N M R}$ (100.6 MHz, $\left.\mathbf{C D C l}_{3}\right): \delta 141.4,138.7,136.4,129.5,128.7,127.1,127.0,126.9,21.4$ ppm.

[3] E. C. Taylor, F. Kienzle, A. McKillop, J. Am. Chem. Soc. 1970, 92, 6088 


\section{${ }^{1} \mathrm{H}$ and ${ }^{13} \mathrm{C}$ NMR Spectra}
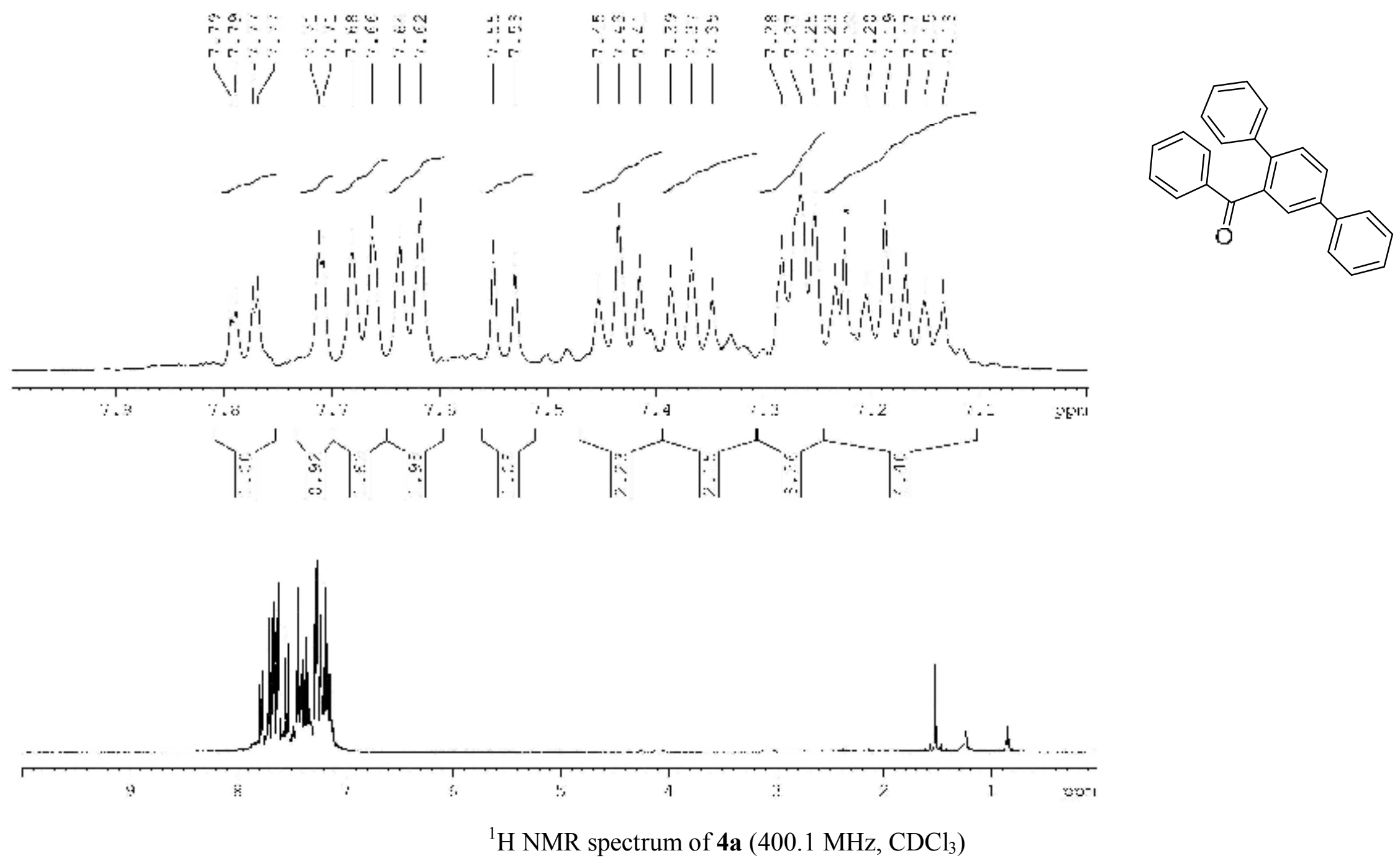


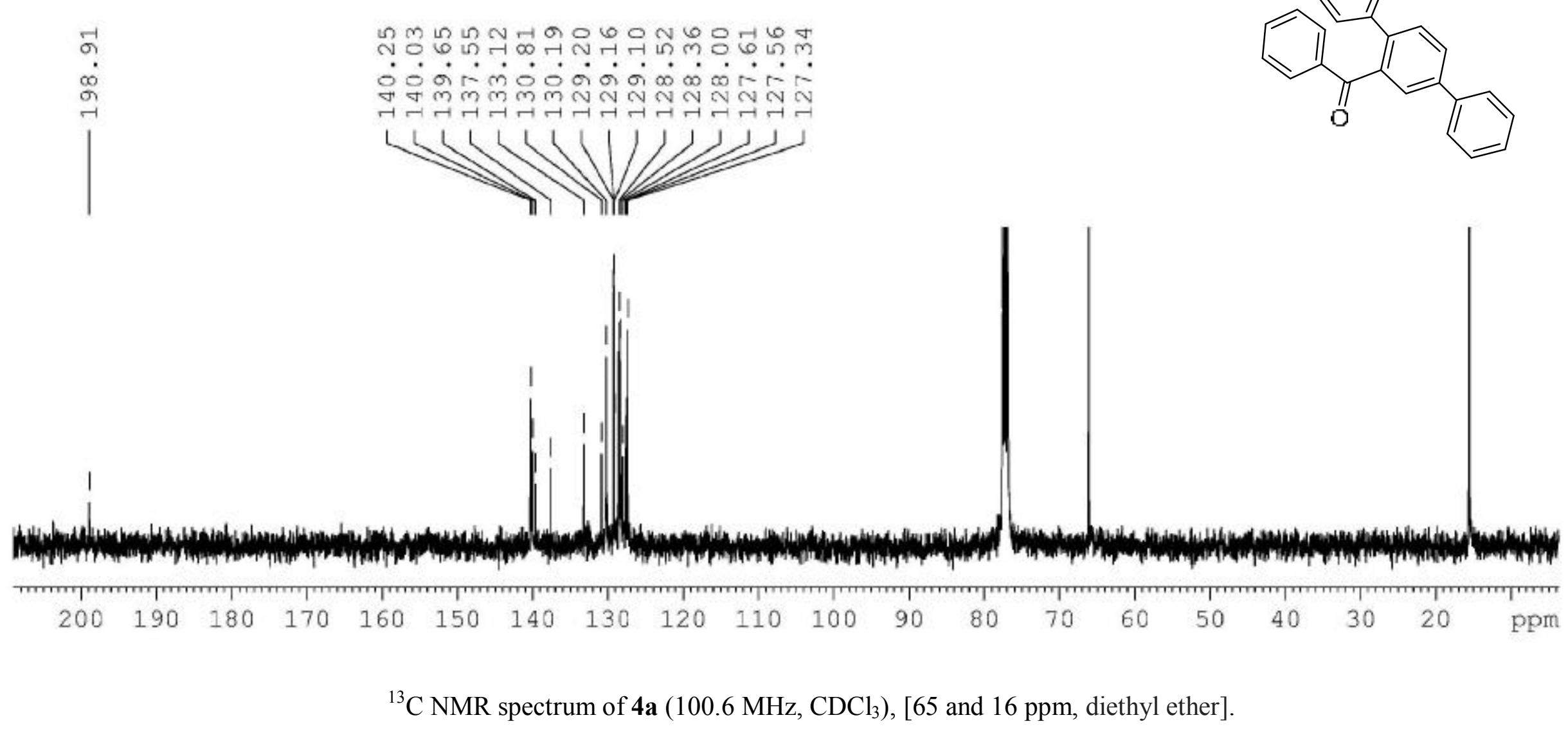




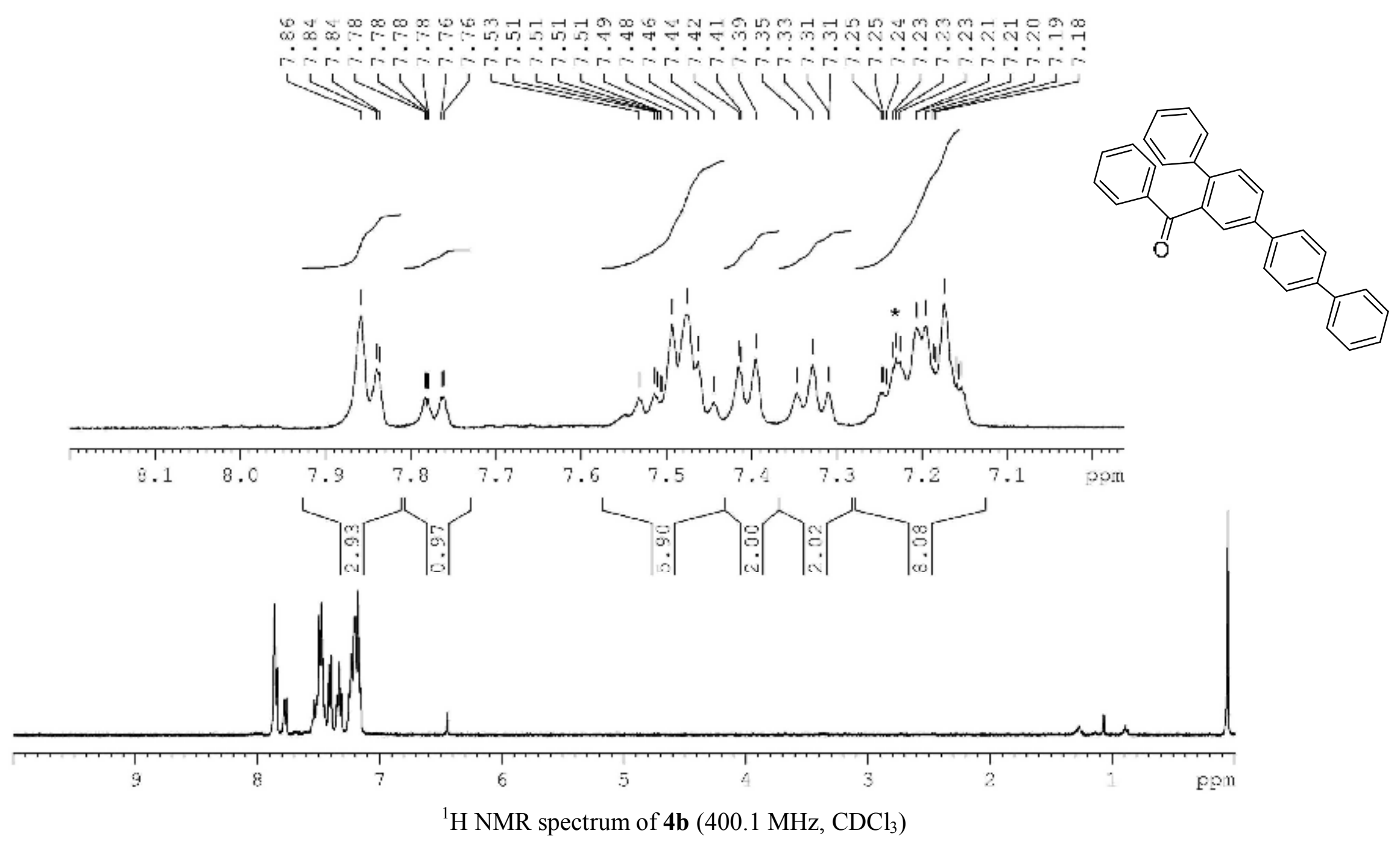




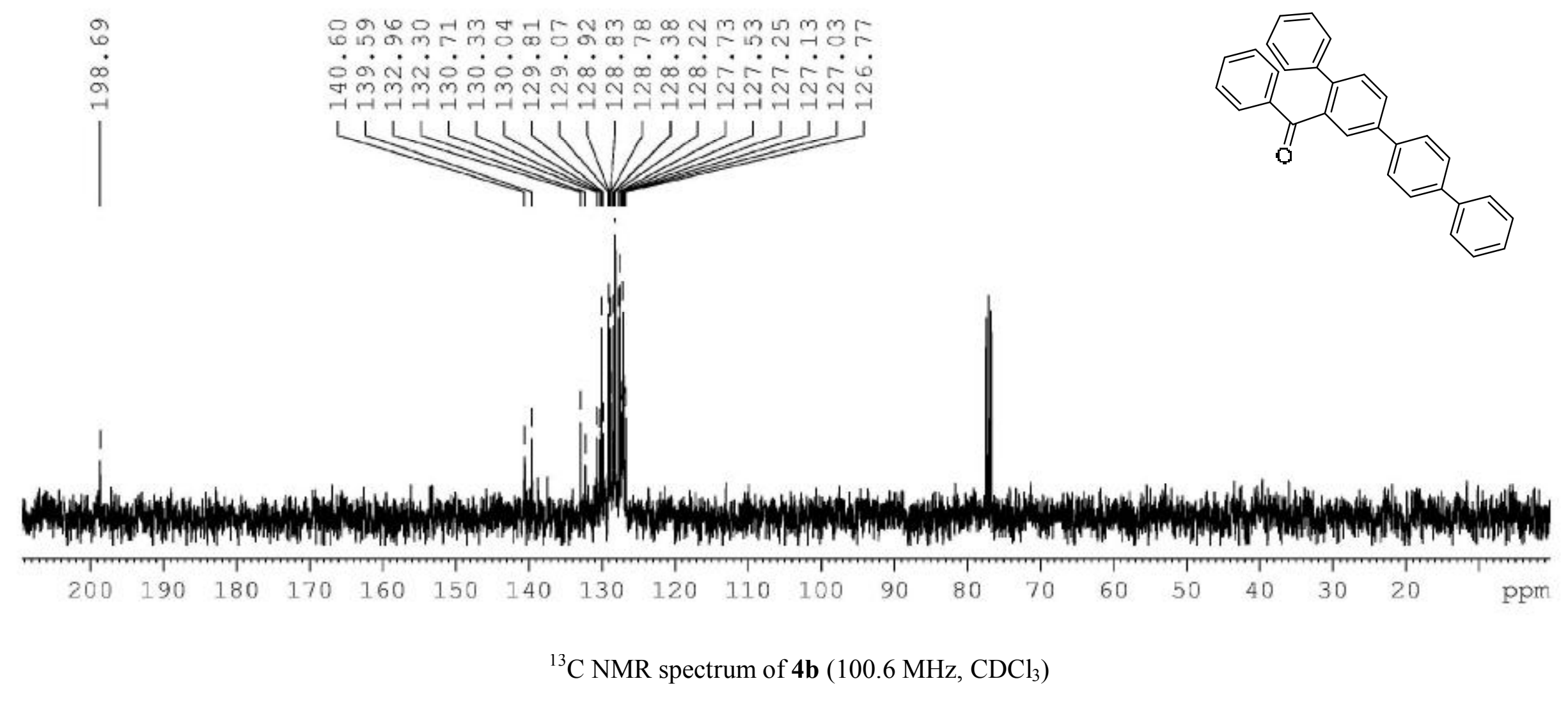



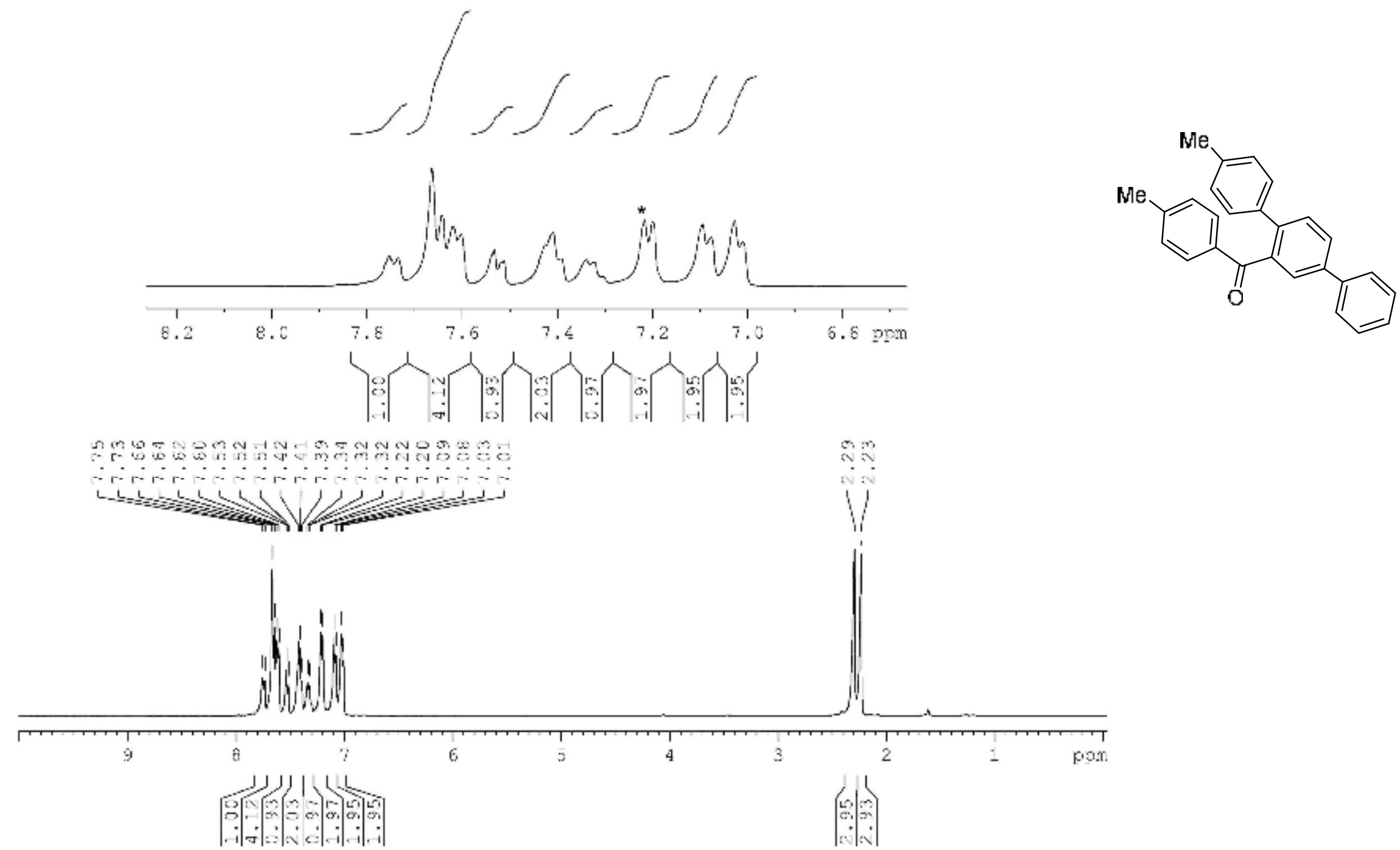

${ }^{1} \mathrm{H}$ NMR spectrum of $\mathbf{4 c}\left(400.1 \mathrm{MHz}, \mathrm{CDCl}_{3}\right)$ 


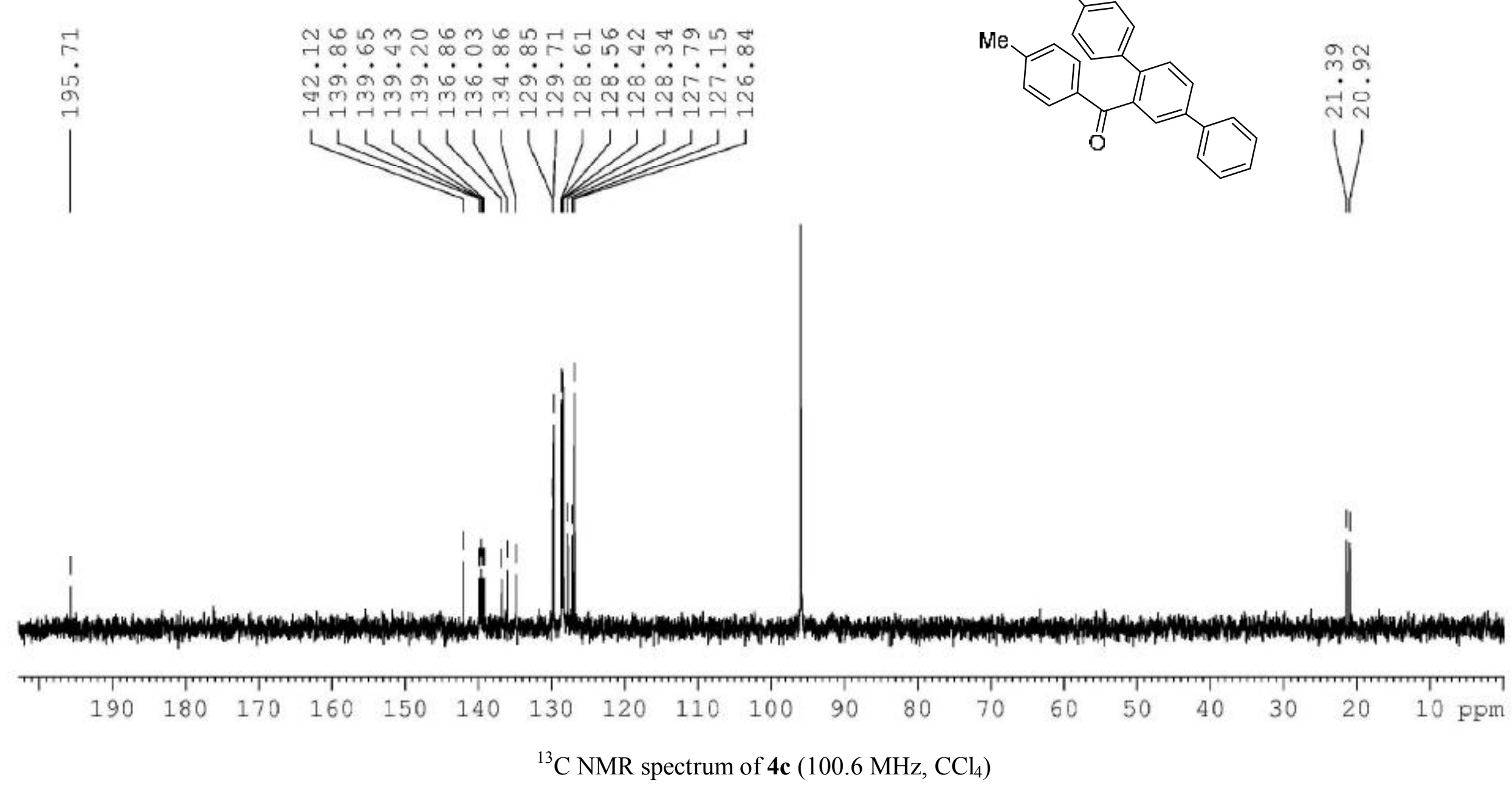



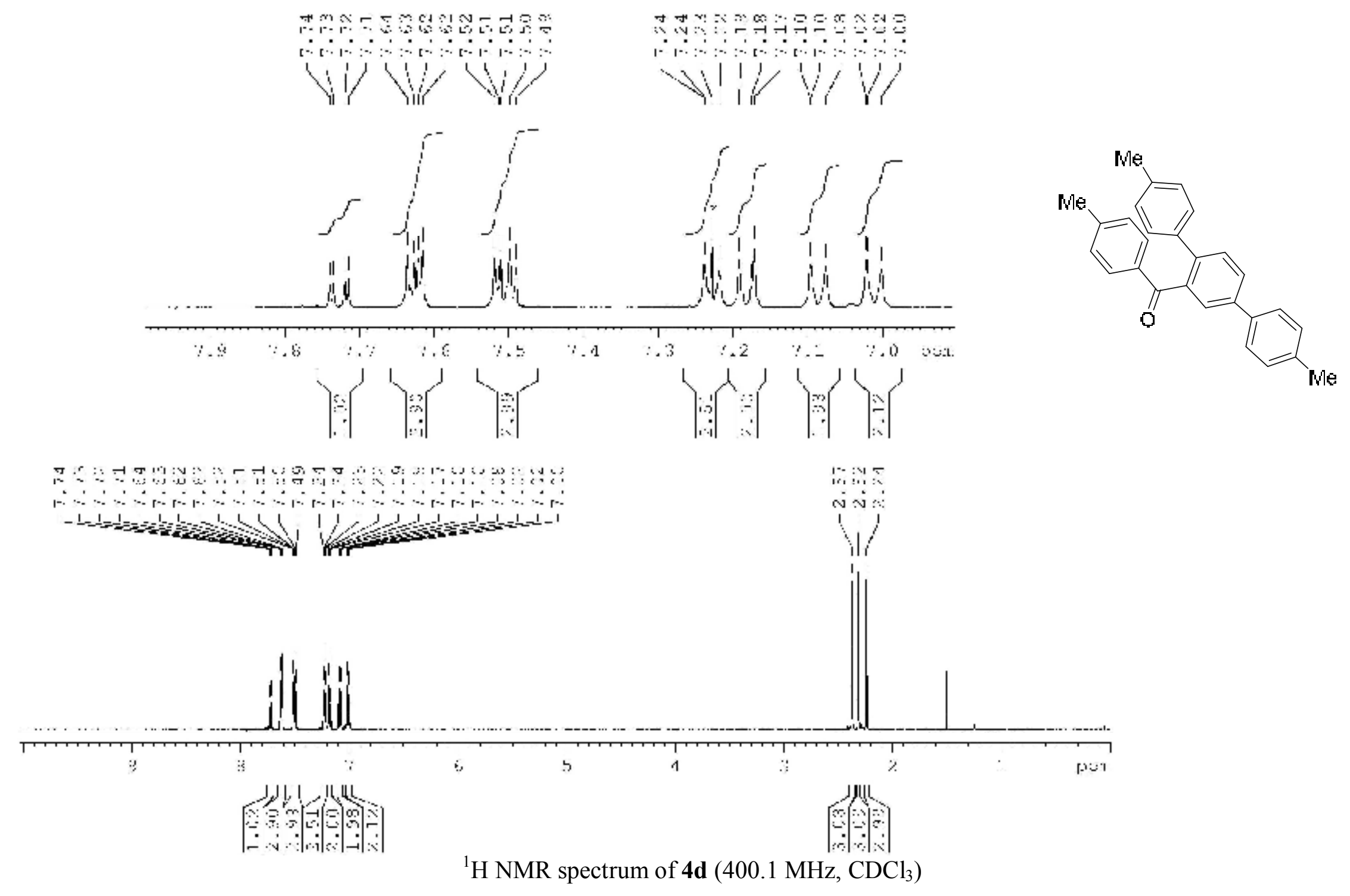


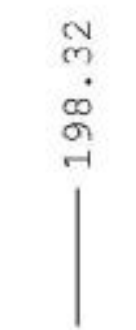

ผ

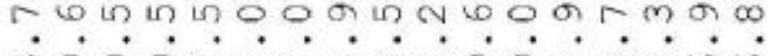

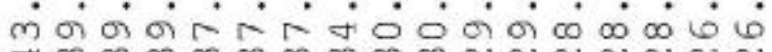

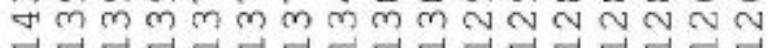

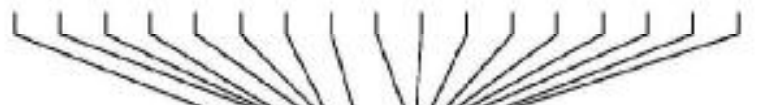

$+1$

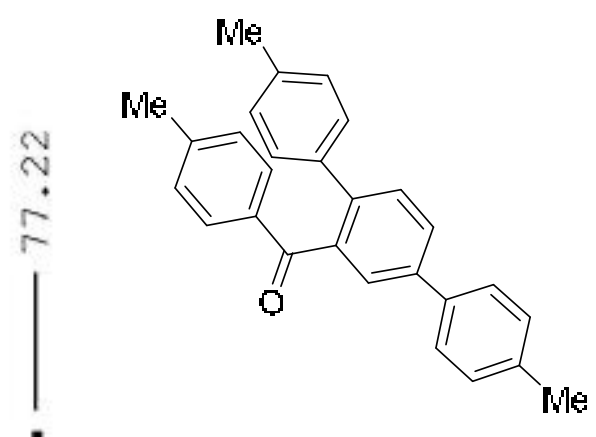

mo 6

\%

다요

$1 /$
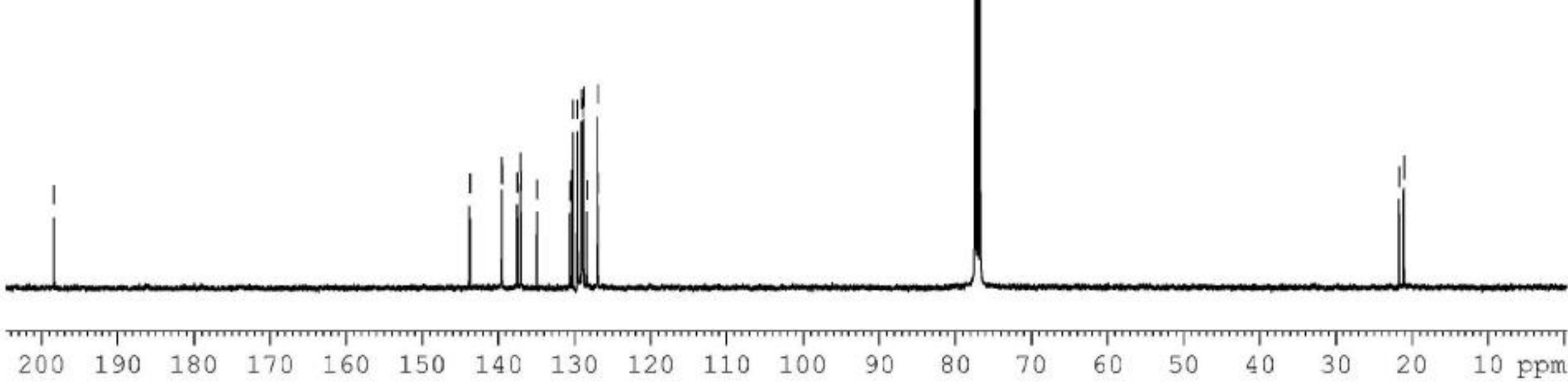

${ }^{13} \mathrm{C}$ NMR spectrum of $4 \mathbf{d}\left(100.6 \mathrm{MHz}, \mathrm{CDCl}_{3}\right)$ 


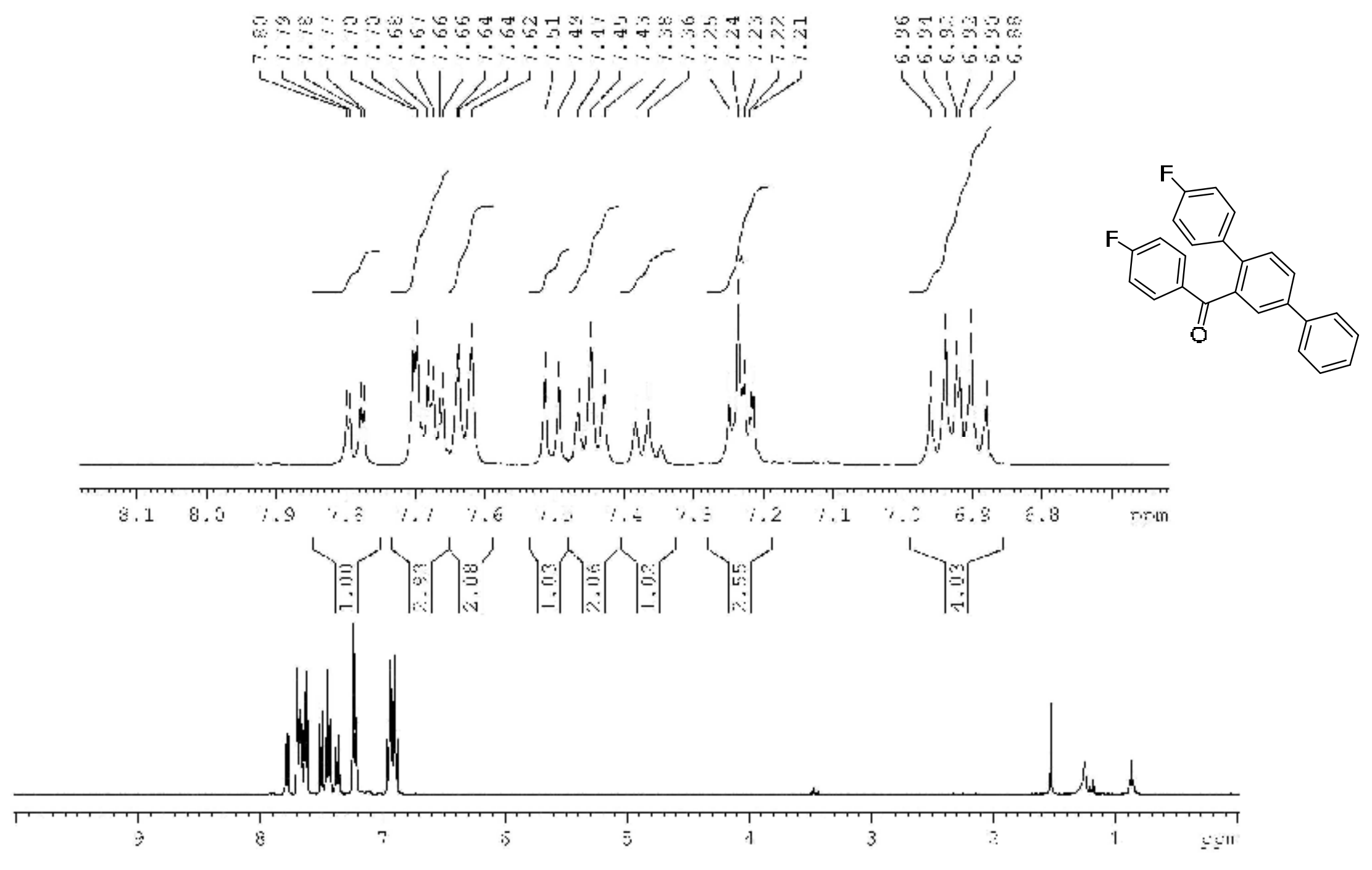

${ }^{1} \mathrm{H}$ NMR spectrum of $4 \mathbf{e}\left(400.1 \mathrm{MHz}, \mathrm{CDCl}_{3}\right)$ 


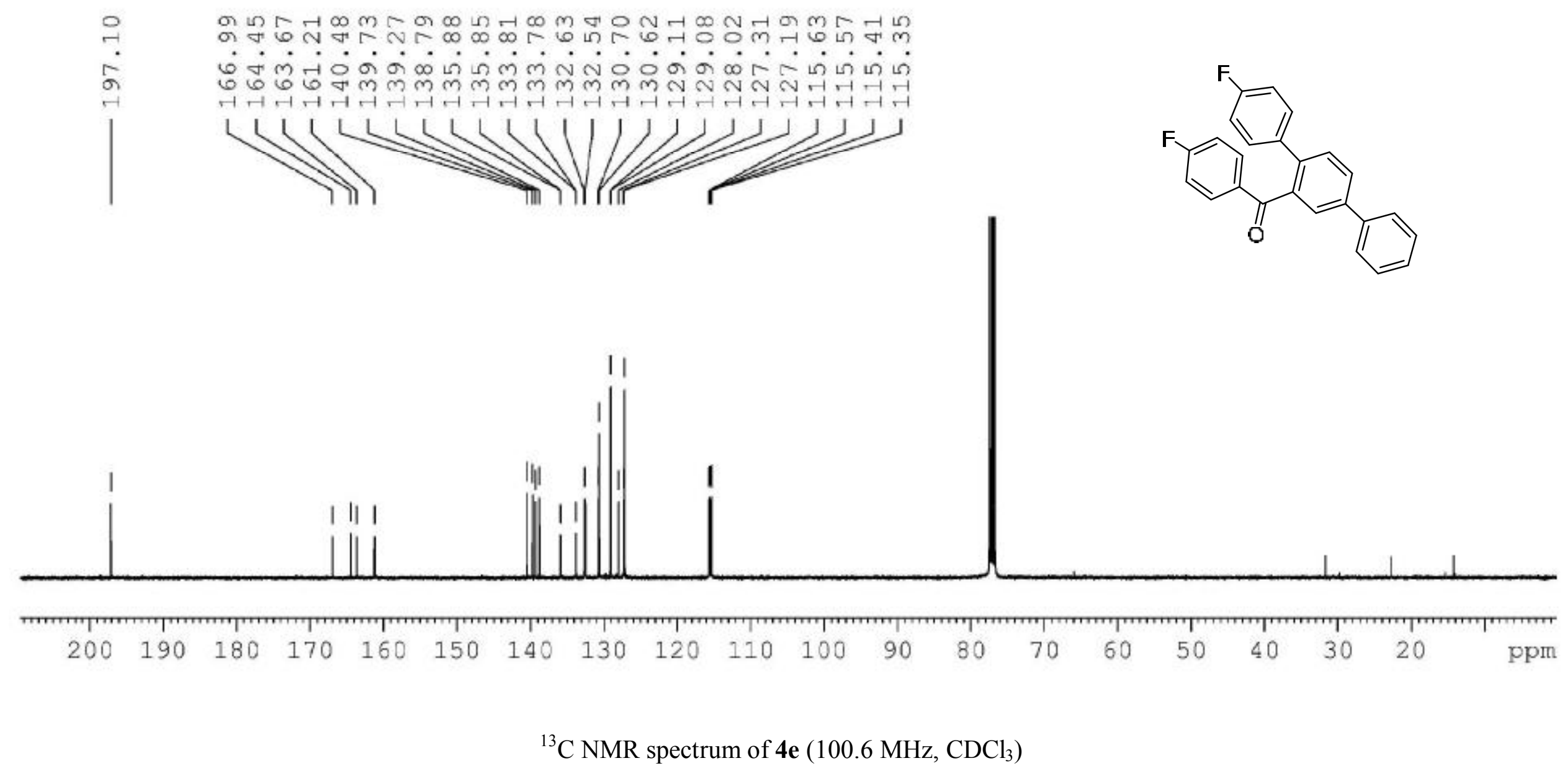




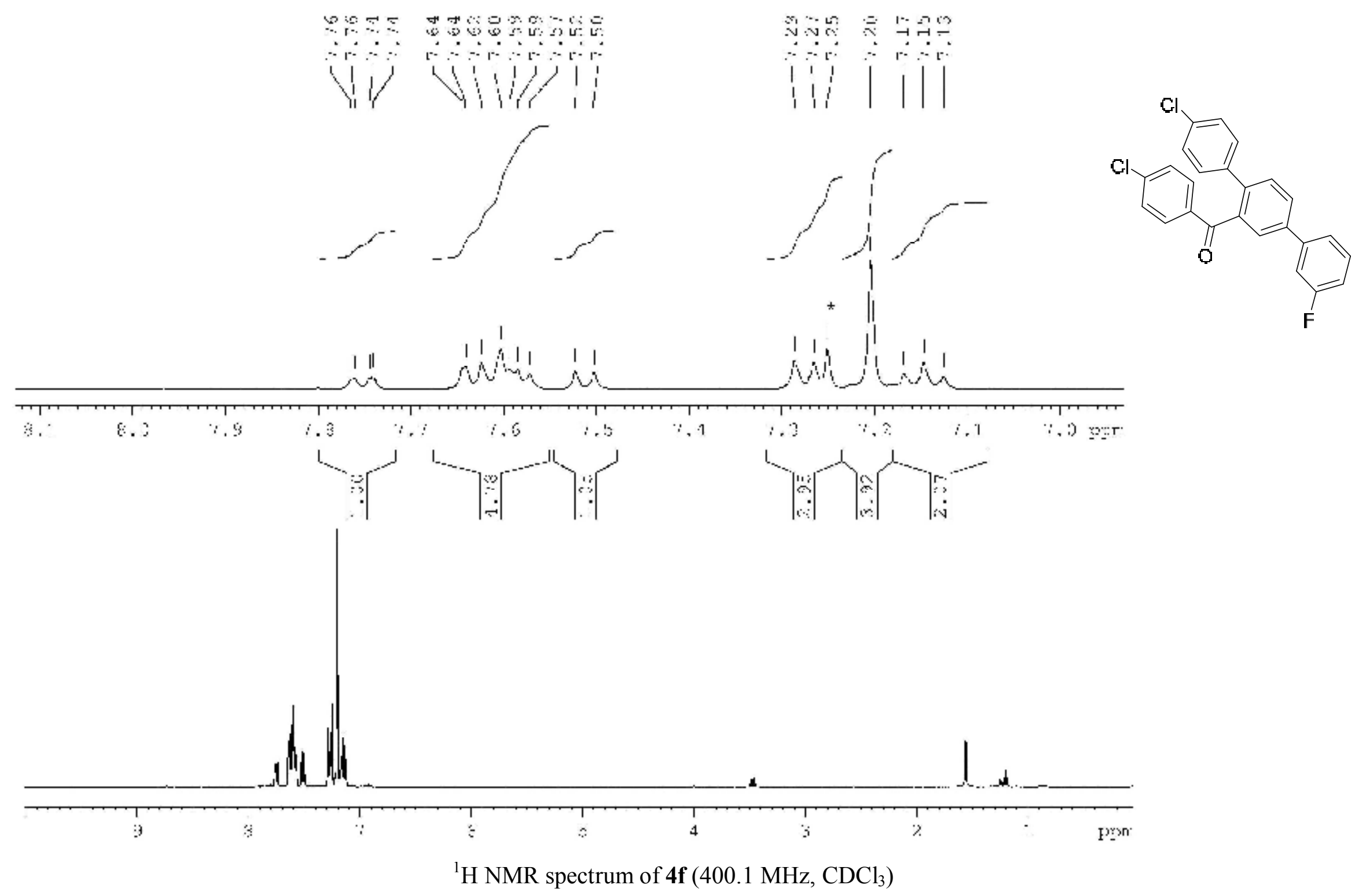




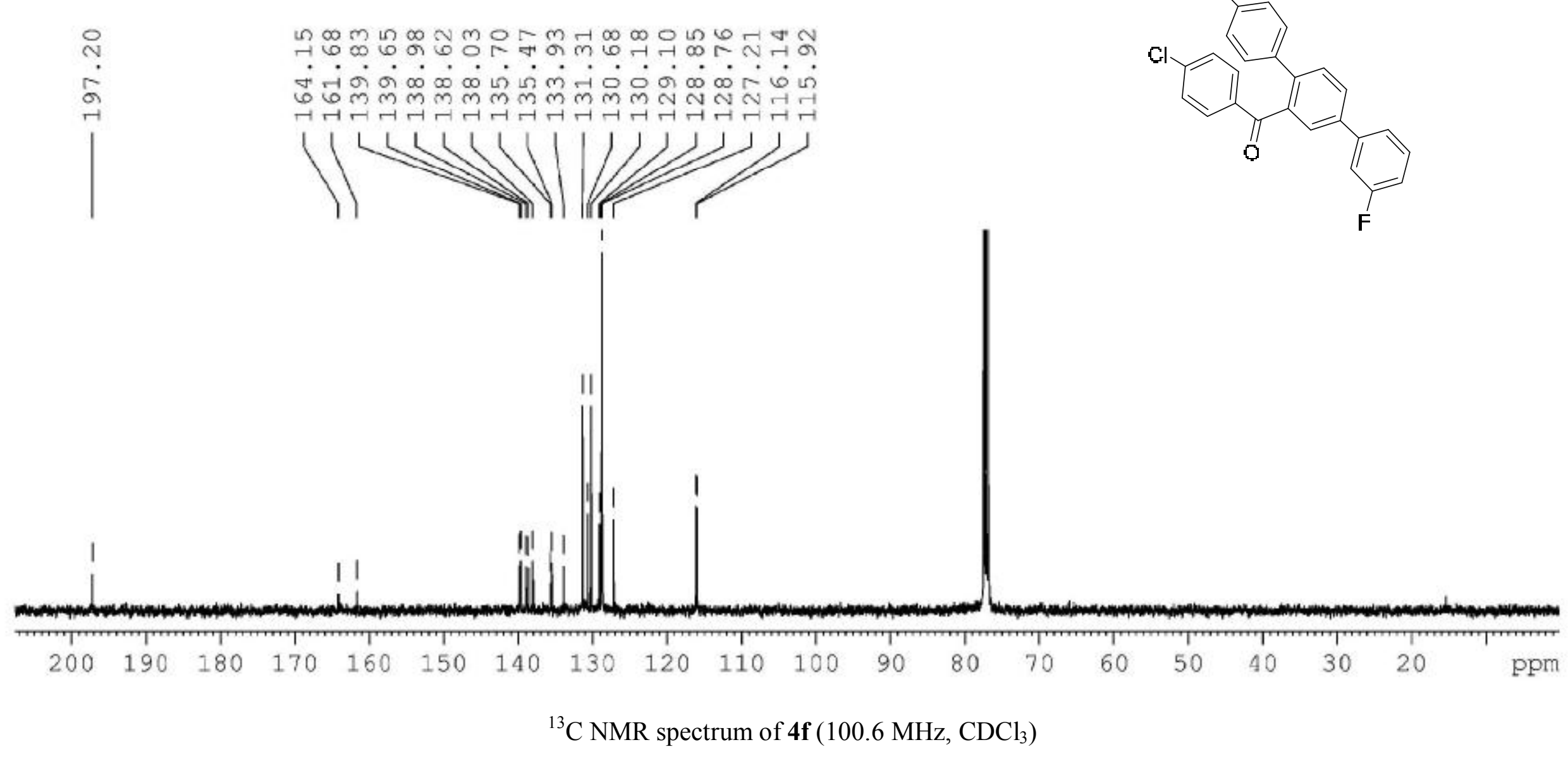




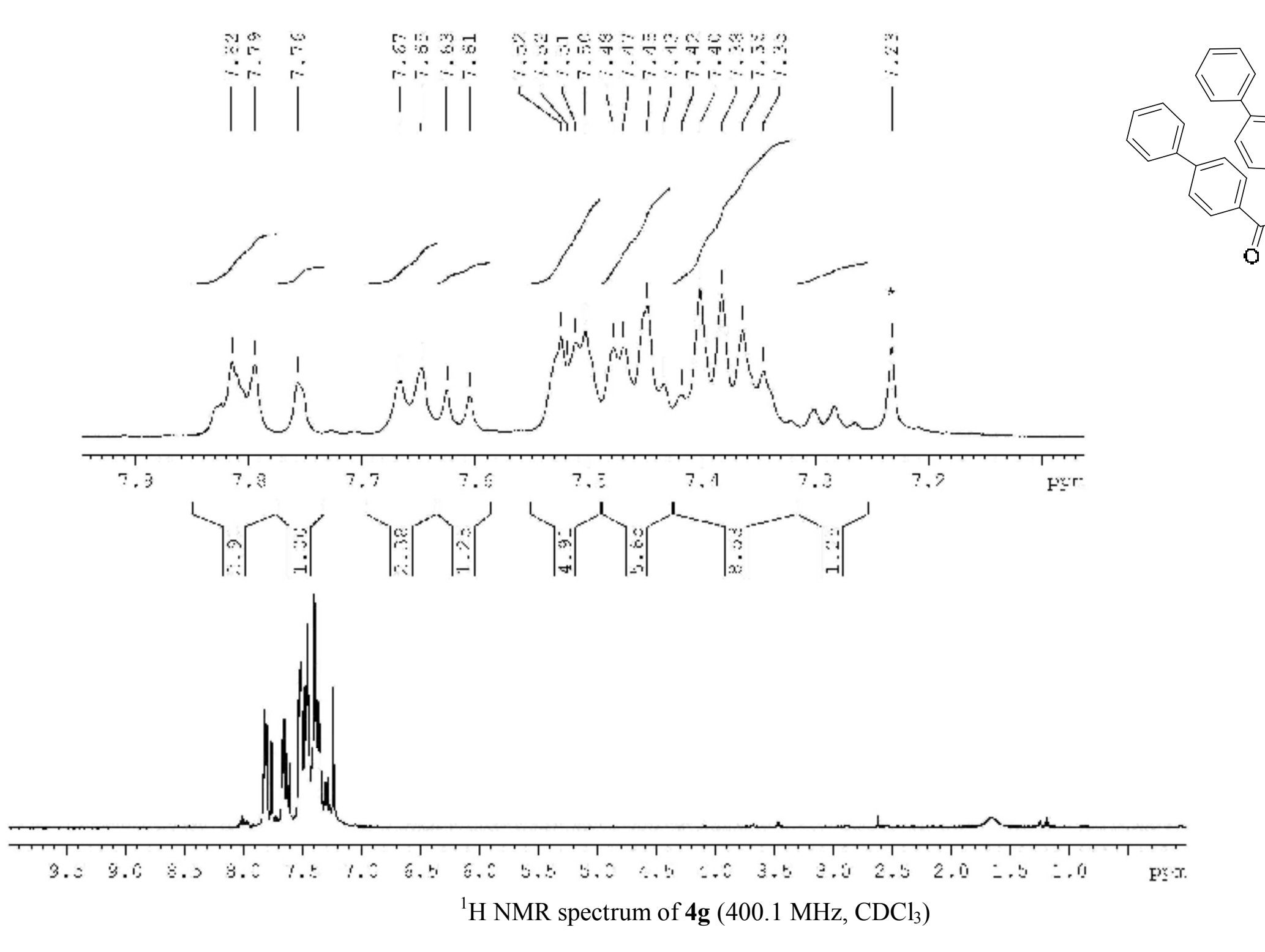




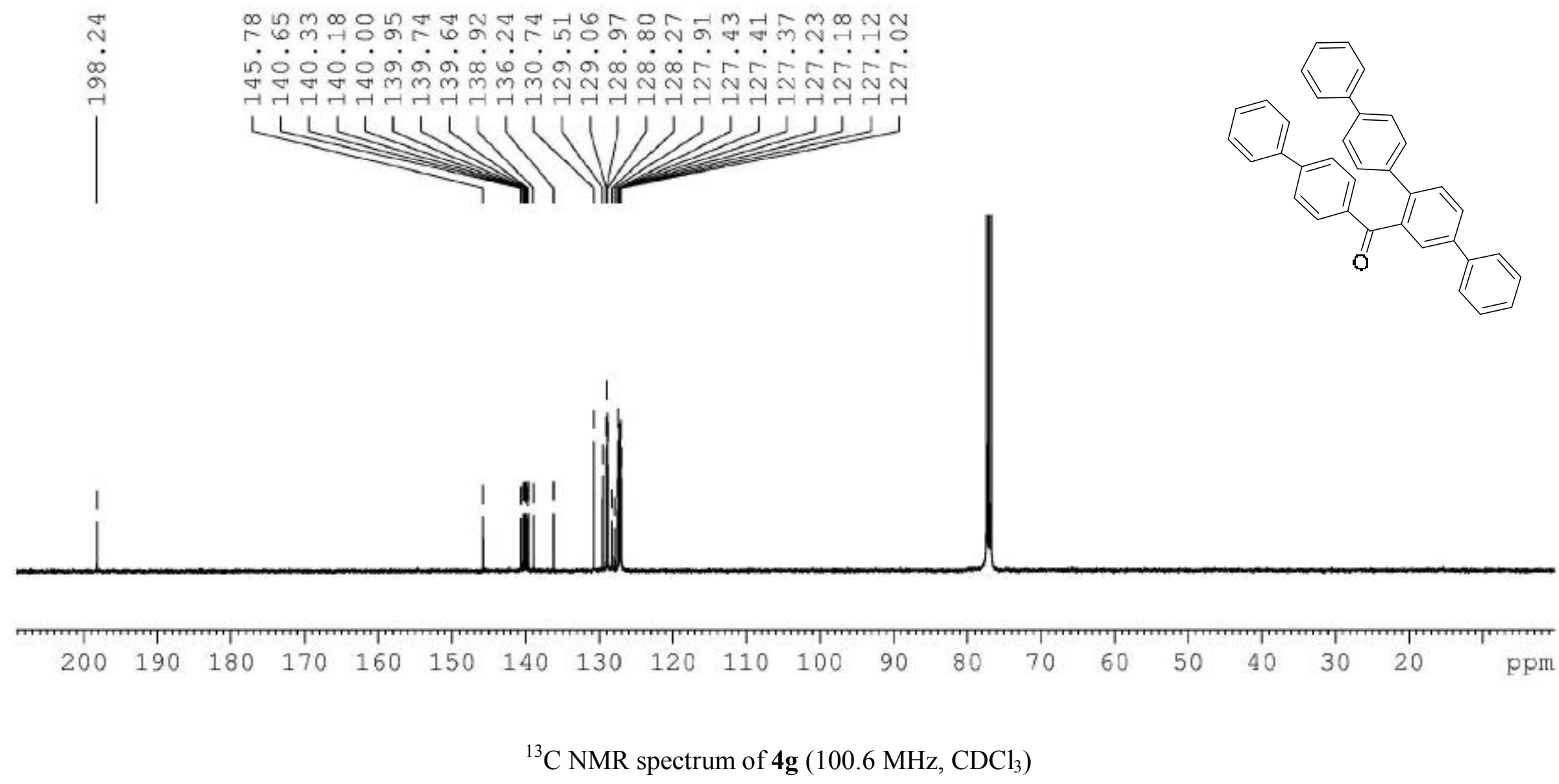




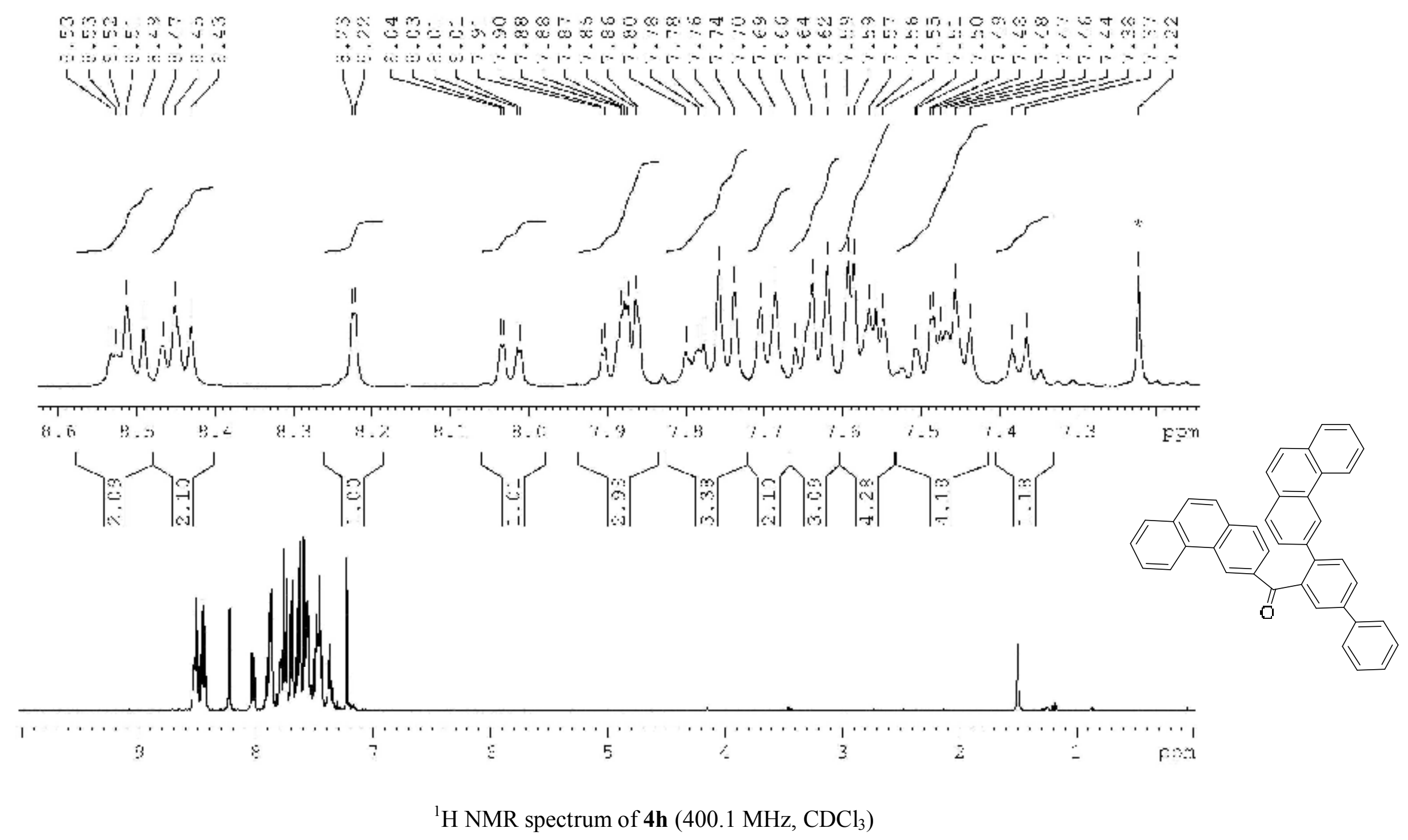




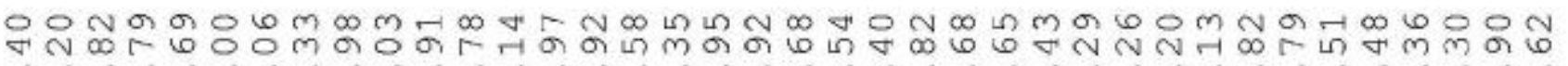
$\dot{0} \dot{0} \dot{0} \dot{0} \dot{0} \dot{0} \dot{0} \dot{0} \dot{0} \dot{0} \dot{0} \dot{0} \dot{0} \dot{0} \dot{0} \dot{0}$ の

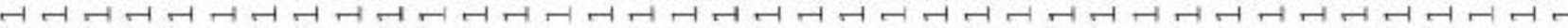

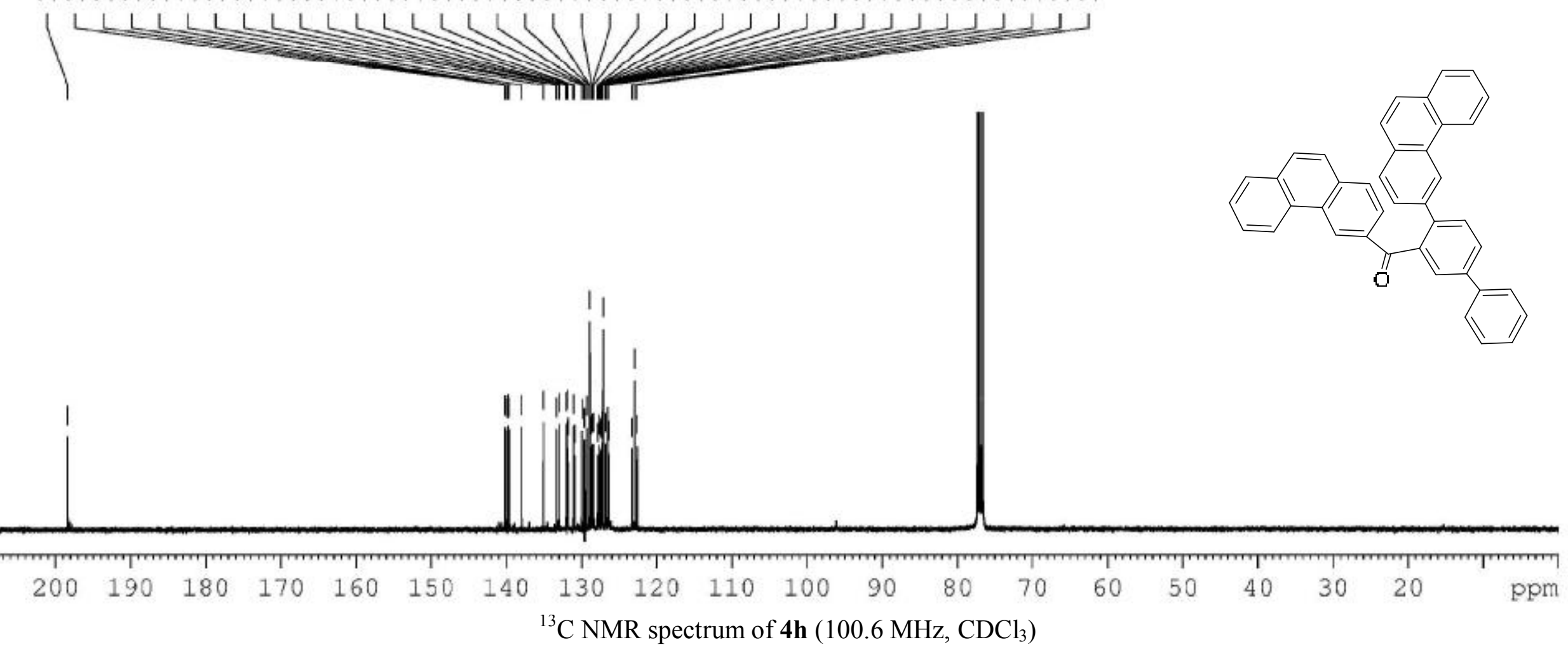



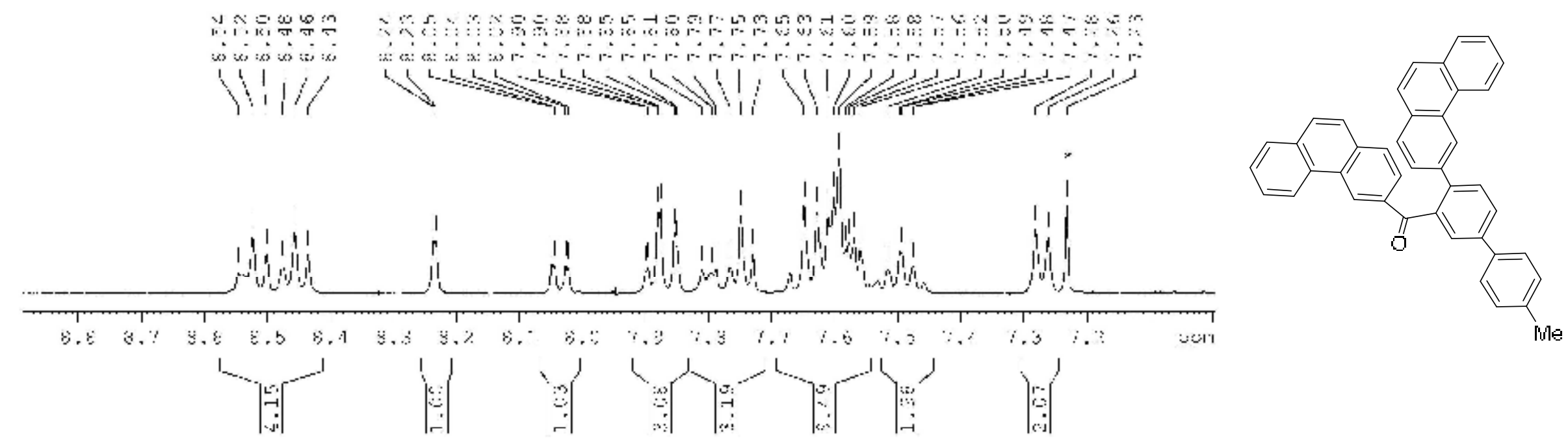

9ง wer

$\mathrm{L}-\mathrm{L}=\mathrm{L}=\mathrm{L}=\mathrm{L}=\mathrm{L}$

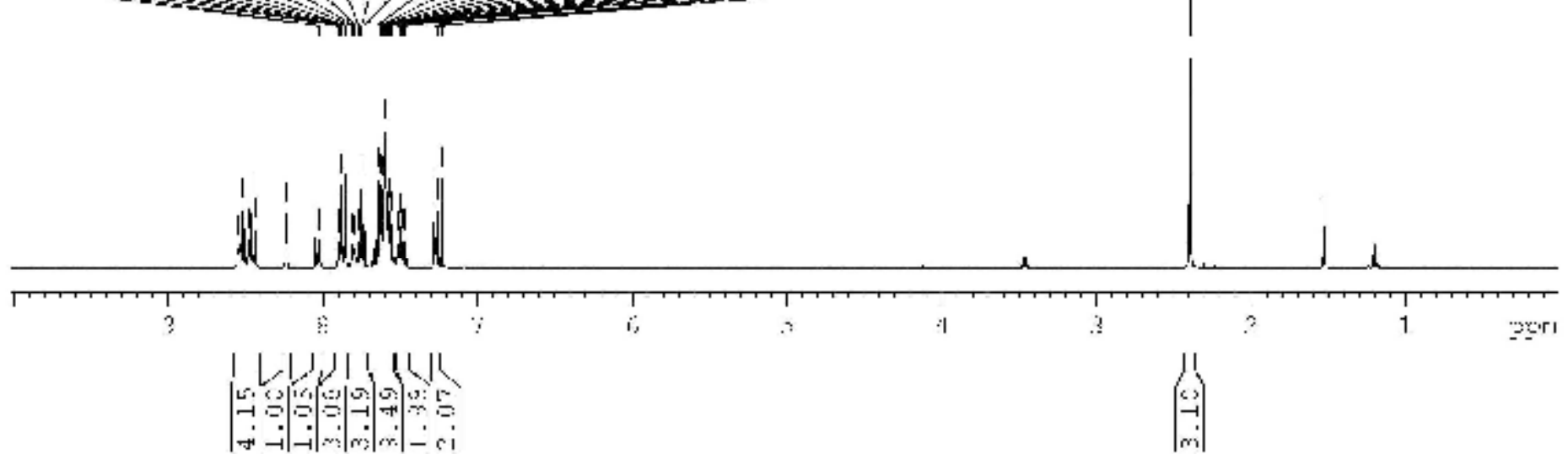

${ }^{1} \mathrm{H}$ NMR spectrum of $4 \mathbf{i}\left(400.1 \mathrm{MHz}, \mathrm{CDCl}_{3}\right)$ 


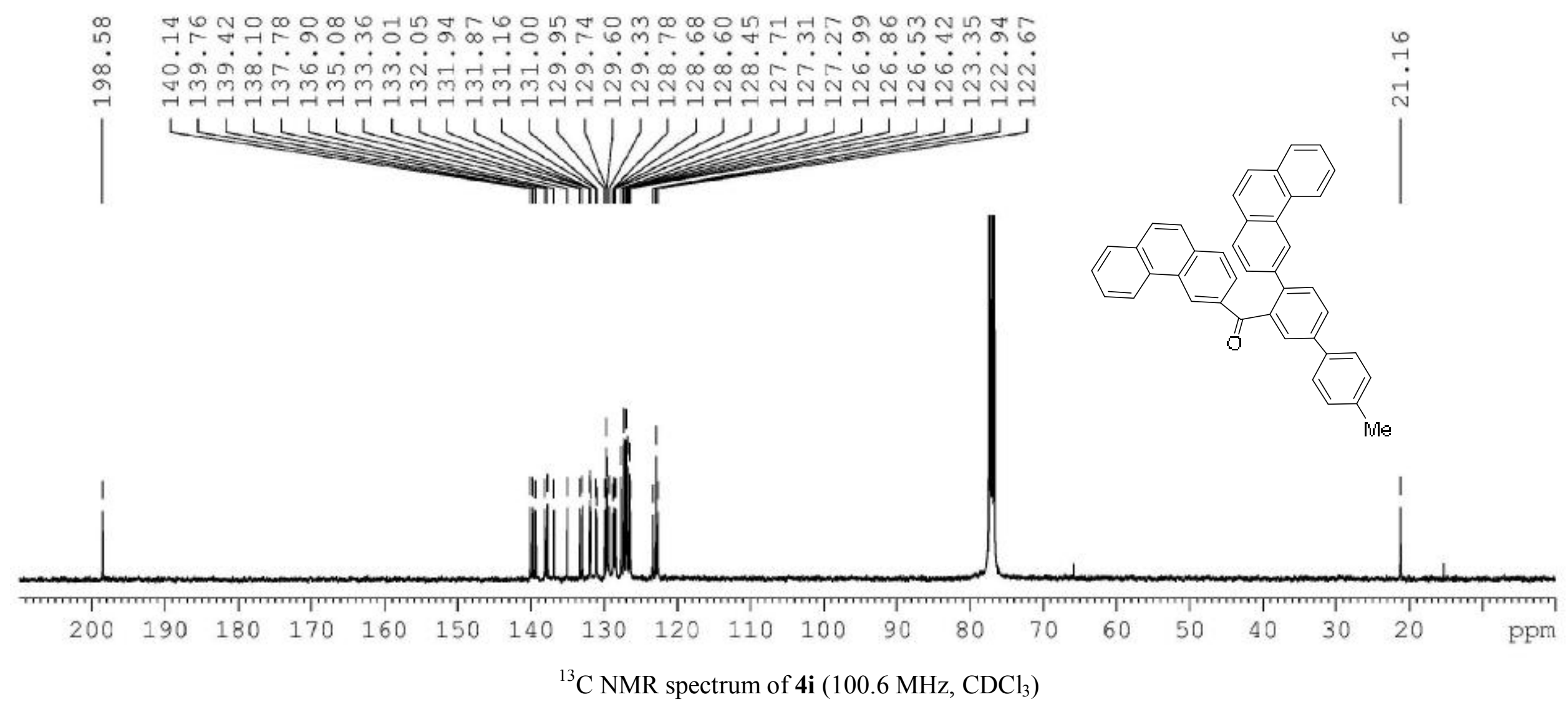




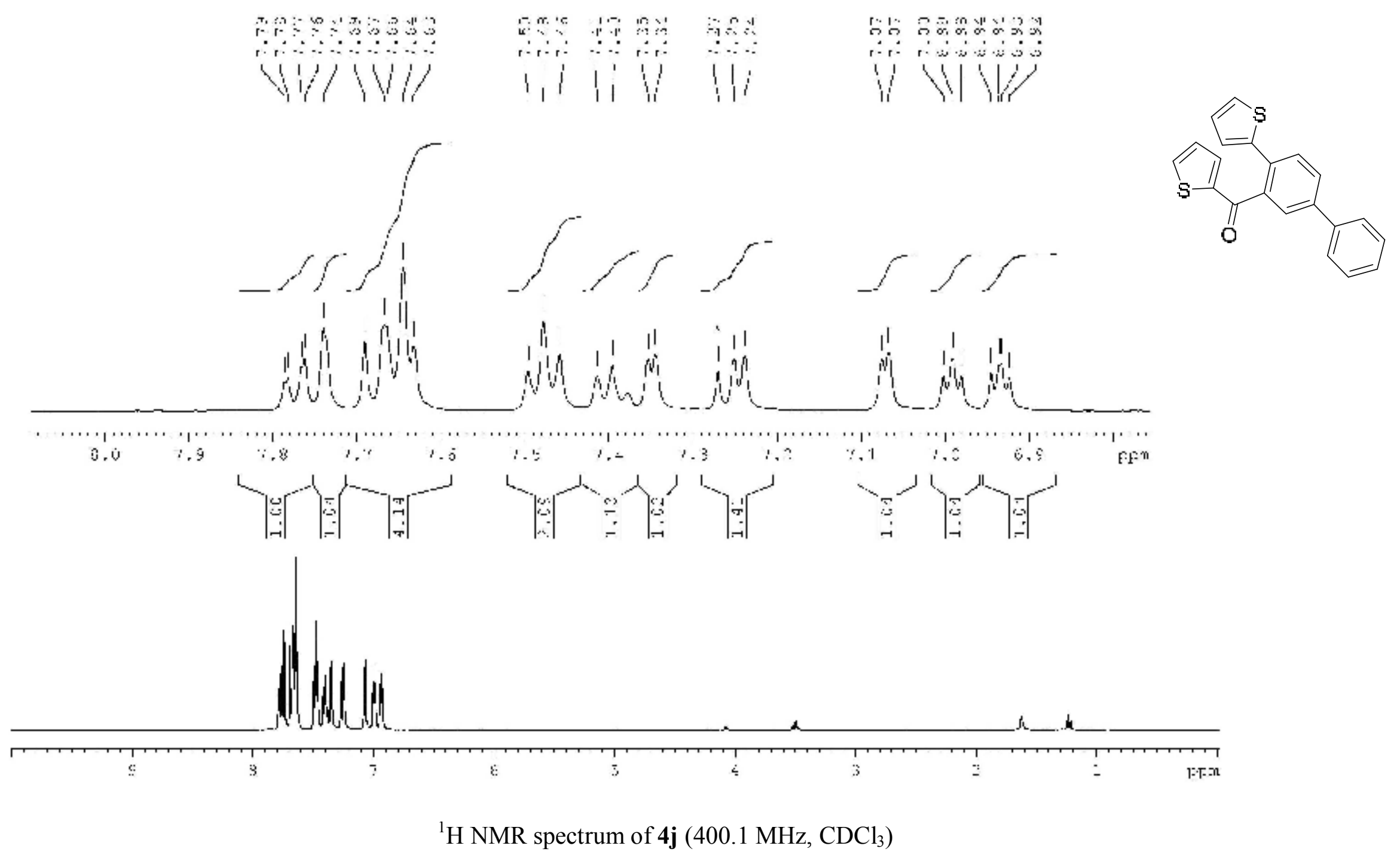




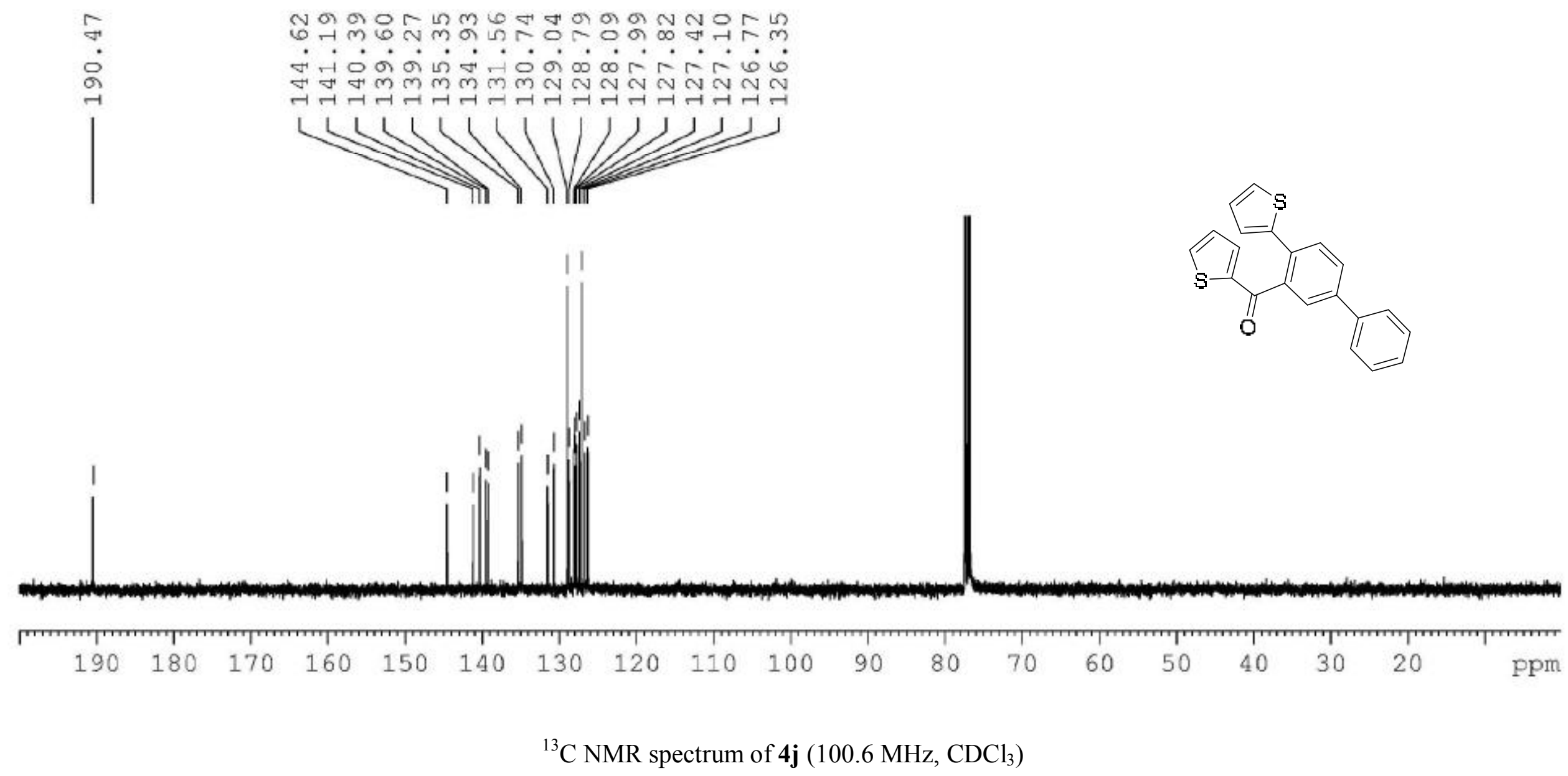


X-Ray Diffraction Analysis. The determination of the unit cell and the data collection for phenyl[1,1';4',1';4",1'"']quarterphenyl-2'-yl-methanone was performed on a Bruker D8 VENTURE PHOTON 100 CMOS diffractometer with $\operatorname{MoK}_{\alpha}$ radiation $(\lambda=0.71073)$ at 100(2) $\mathrm{K}$ using the $\omega-\varphi$ scan technique. A specimen of $\mathrm{C}_{31} \mathrm{H}_{22} \mathrm{O}$, approximate dimensions $0.084 \mathrm{~mm} \times 0.180 \mathrm{~mm} \times 0.500 \mathrm{~mm}$, was used for the X-ray crystallographic analysis. The Xray intensity data were measured. The integration of the data using a triclinic cell with P-1 space group yielded a total of 74952 reflections to a maximum $\theta$ angle of $29.70^{\circ}(0.72 \AA$ resolution), of which 5899 were independent (average redundancy 12.706, completeness $=$ $96.6 \%$, Rint $=6.10 \%$, Rsig $=3.12 \%)$ and $4677(79.28 \%)$ were greater than $2 \sigma(F 2)$. The final cell constants of $\mathbf{a}=6.8890(11) \AA, \mathbf{b}=9.4737(17) \AA, \mathbf{c}=17.281(3) \AA, \alpha=74.545(6)^{\circ}, \beta=$ $87.819(6)^{\circ}, \gamma=80.703(6)^{\circ}$, volume $=1072.8(3) \AA^{3}$, are based upon the refinement of the XYZ-centroids of 9314 reflections above $20 \sigma(\mathrm{I})$ with $4.517^{\circ}<2 \theta<58.09^{\circ}$. Data were corrected for absorption effects using the multi-scan method (SADABS). The ratio of minimum to maximum apparent transmission was 0.922. The calculated minimum and maximum transmission coefficients (based on crystal size) are 0.9630 and 0.9940 . . The structure was solved and refined using the Bruker SHELXTL Software Package. ${ }^{[4]}$

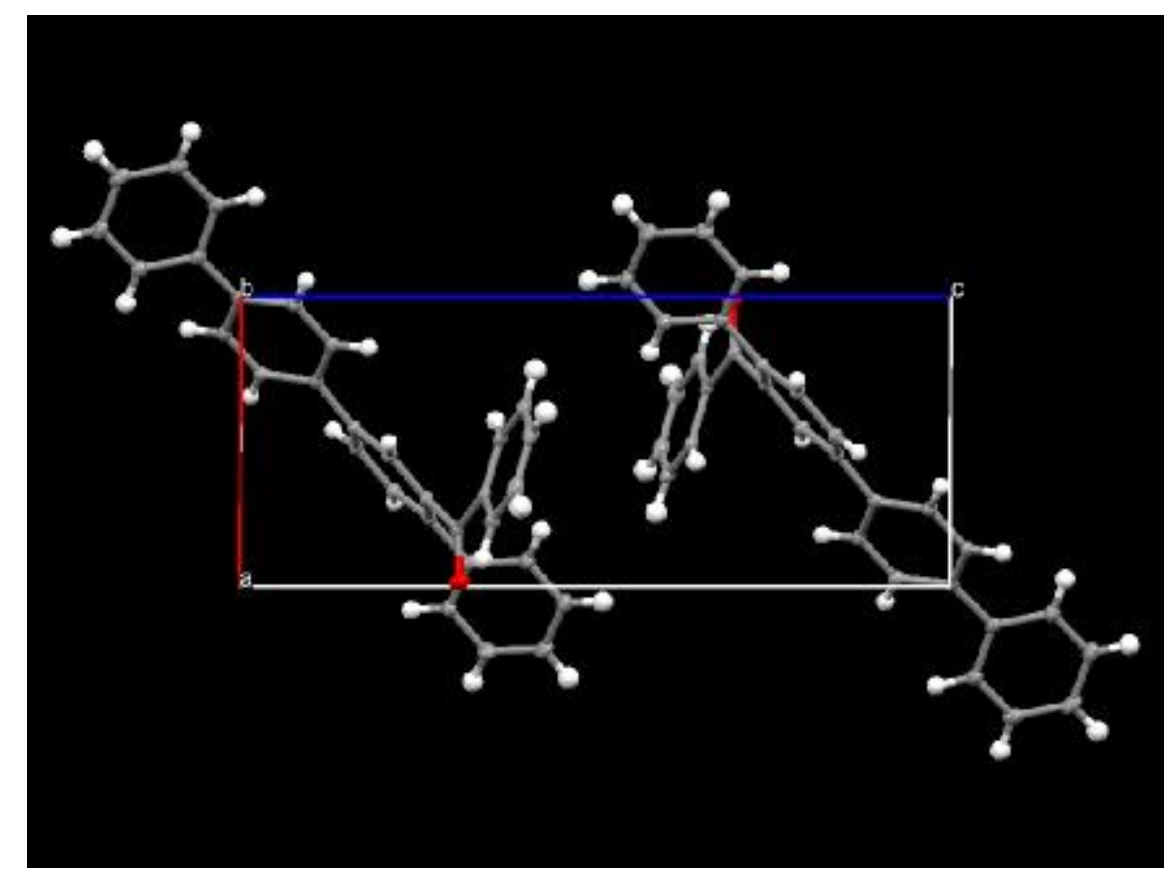

Figure 1. X-ray data on unit cell of phenyl[1,1';4',1'";4",1"', ]quarterphenyl-2'-ylmethanone (4b).

[4] G. M. Sheldrick, Acta Crystallogr. 2008, D64, 112. 
The final anisotropic full-matrix least-squares refinement on F2 with 289 variables converged at $\mathrm{R} 1=4.62 \%$, for the observed data and $\mathrm{wR} 2=13.97 \%$ for all data. The goodness-of-fit was 1.027. The largest peak in the final difference electron density synthesis was 0.40 e- $/ \AA 3$ and the largest hole was -0.380 e- $/ \AA 3$ with an RMS deviation of 0.069 e- $/ \AA 3$. On the basis of the final model, the calculated density was $1.271 \mathrm{~g} / \mathrm{cm} 3$ and $F(000), 432$ e-.

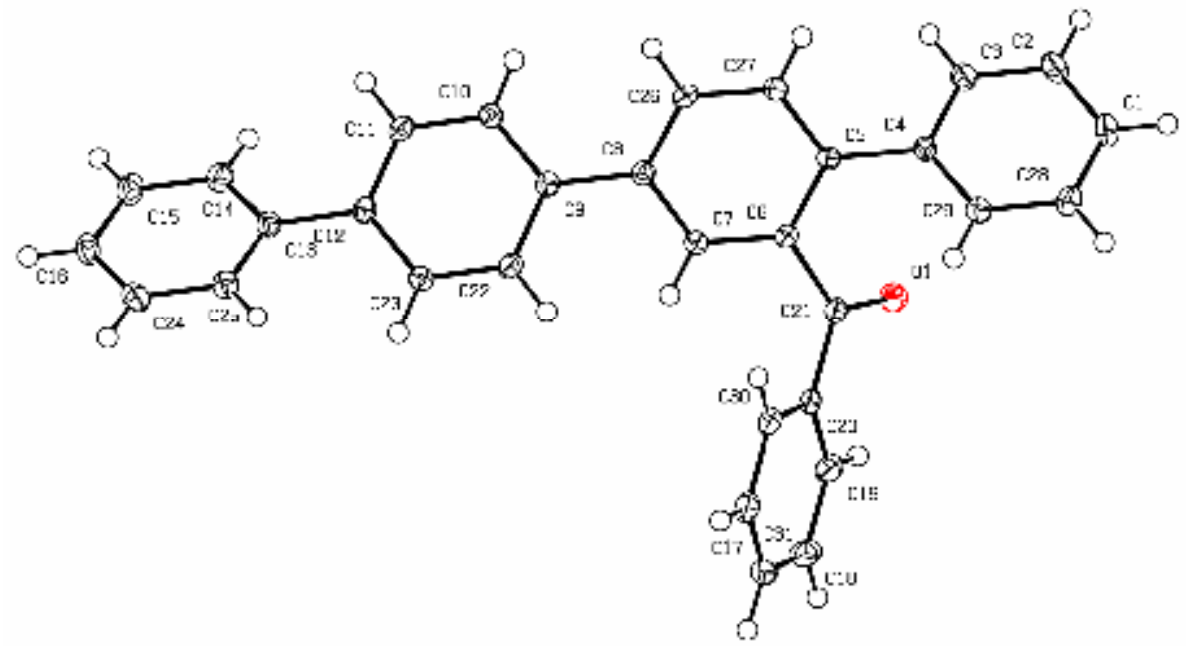

Figure 2. X-ray structure phenyl[1,1';4',1',;4",1"'] quarterphenyl-2'-yl-methanone (4b). Thermal ellipsoids set at $50 \%$ probability.

Atomic coordinates, bond lengths, bond angles and thermal parameters have been deposited at the Cambridge Crystallographic Data Centre (CCDC) and allocated the deposition numbers CCDC 1453334 (4b). These data can be obtained free of charge from the Cambridge Crystallographic Data Centre via www.ccdc.cam.ac.uk/data_request/cif. 